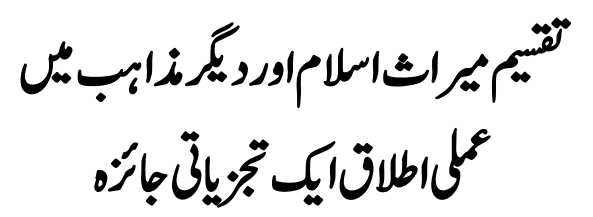

\title{
Distribution of Inheritance in Islam and other Religions: its application and analytical review
}

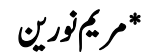

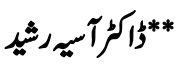

\begin{abstract}
It is clear from orders of inheritance that the religion Islam gives right to every human. It adopts numerous procedures for the purpose of giving rights, which, in one form, becomes the law of inheritance. In this law, after death of a person, his remaining proprietorship becomes the proprietorship of his legal heirs. The deceased person's wife, children, father, and mother etc. are entitled to his proprietorship. In the religion of Islam, there are not only orders regarding Islamic share of legal heirs, but also the deceased has been given the right in his lifetime that he can give his whole or part proprietorship to poor and rightful people. It is because the proprietorship of the deceased person should not come to hands of illegal persons, while the said proprietorship can equally be distributed among the authorized legal heirs/persons. Legacy is also the right of females as given in the Sunnah and Holy Quran. But in present days, Muslims follow other religions, and do not give the Islamic share to the women, which will badly affect them at the Day of Judgment. This article has discussed the rights of women in Islam regarding inheritance.
\end{abstract}

Key Words: Law of Inheritance, Legal heirs, Legacy,Day of Judgment.

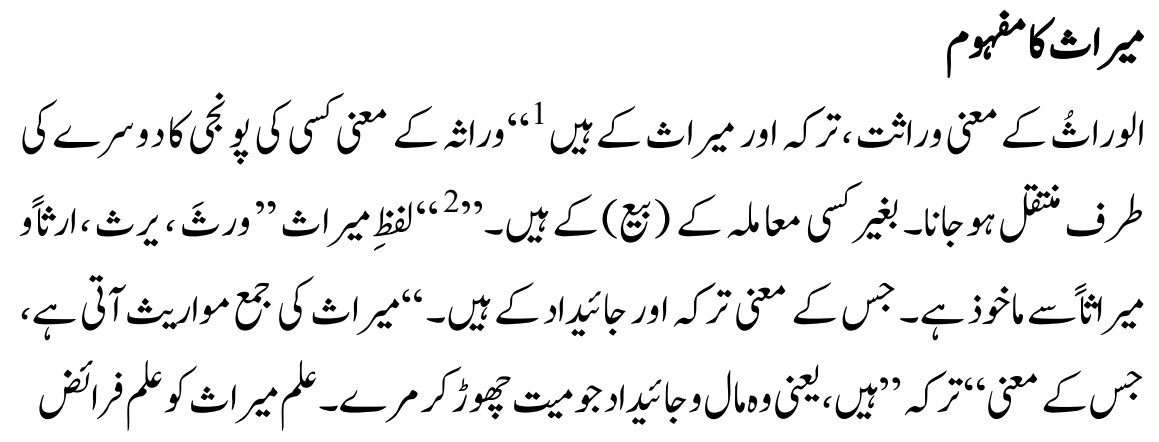

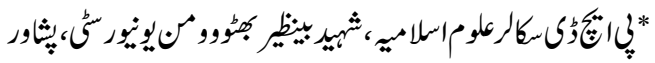

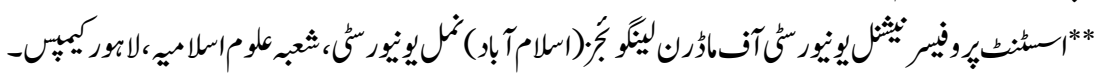




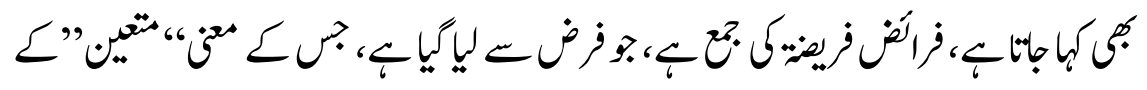

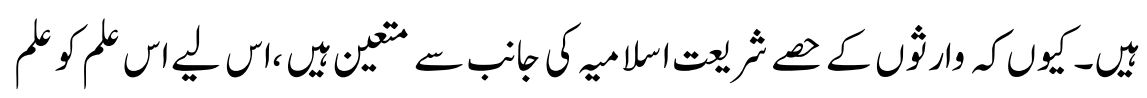

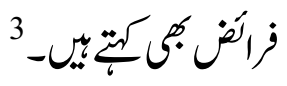

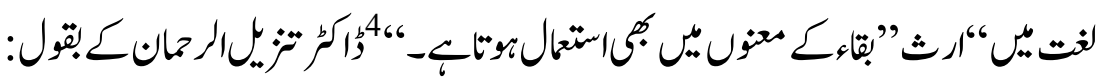

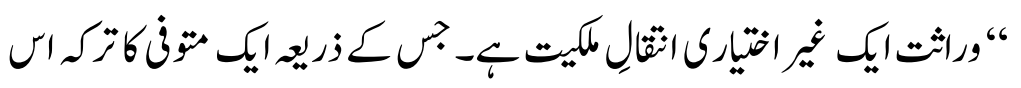

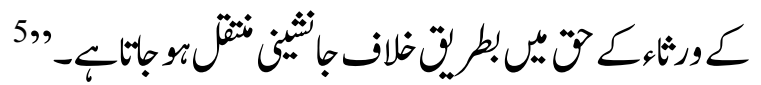

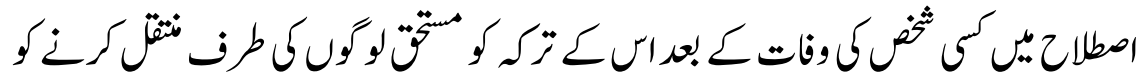

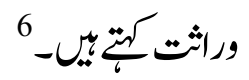

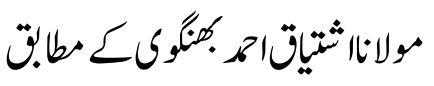

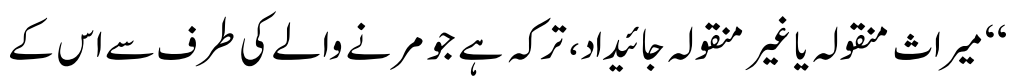

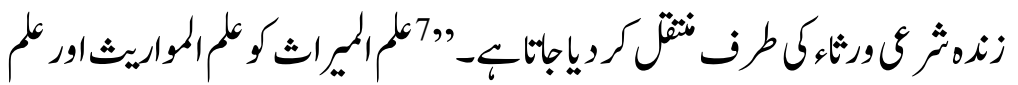

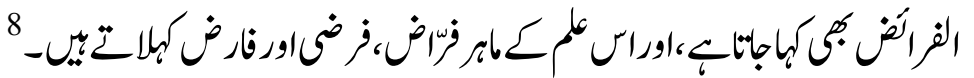

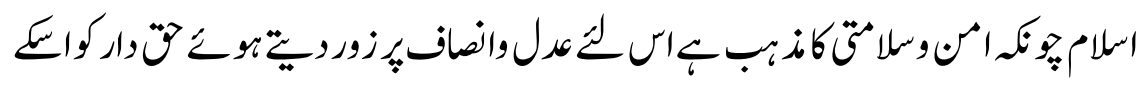

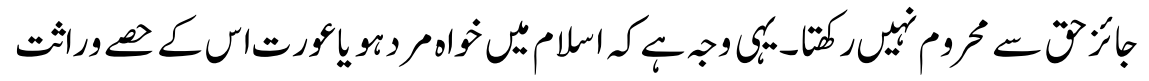

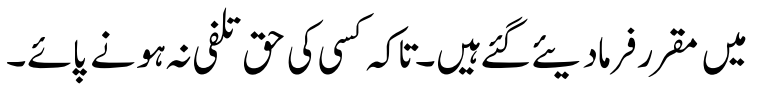

$$
\begin{aligned}
& \text { كتّف نذابب|ور ثتيمثيراث }
\end{aligned}
$$

ميكويت

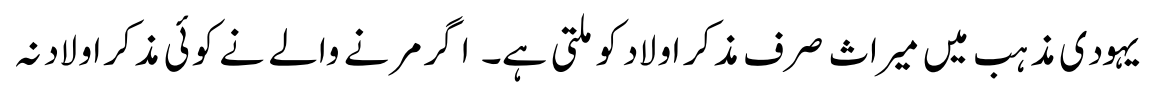

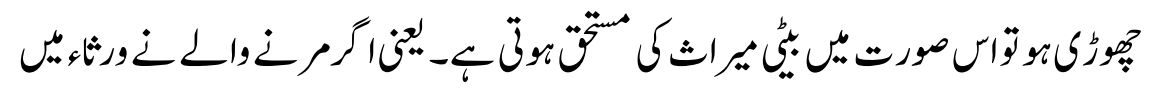

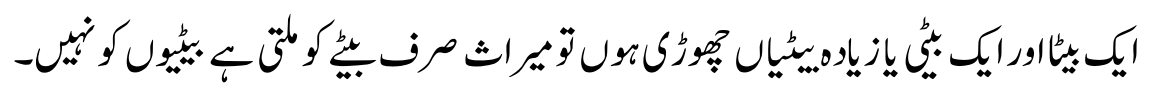

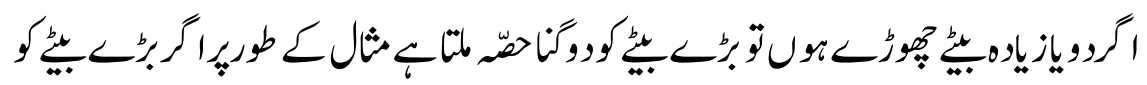




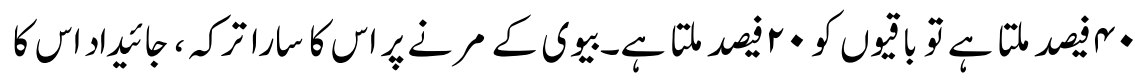

$$
9 \text { ثوبر ليتاك }
$$

ثياتيت

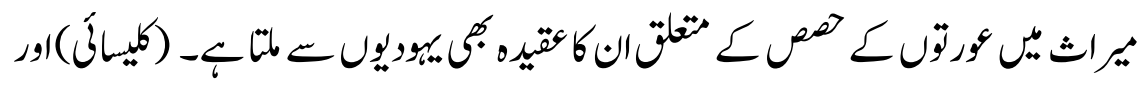

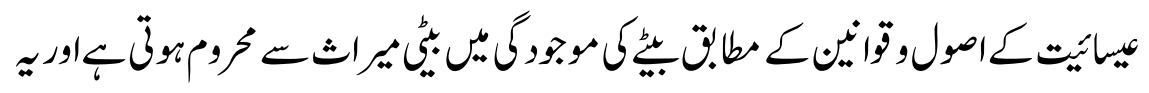
Ecclesiastical

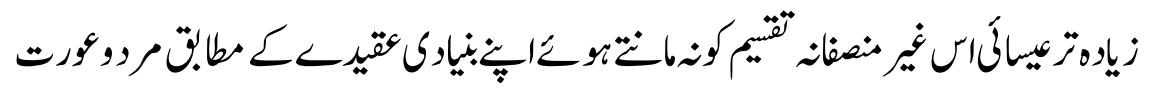

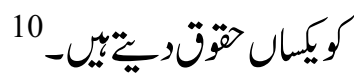

: مبوكنيرات

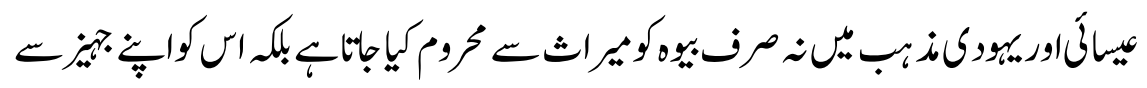

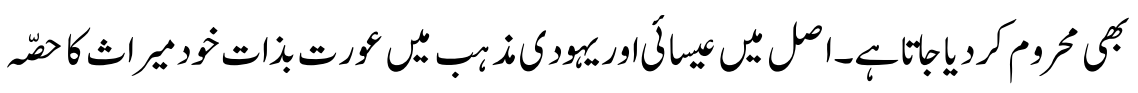

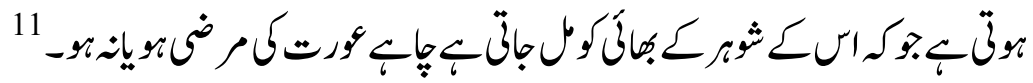

مندومت

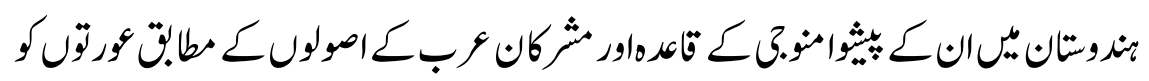

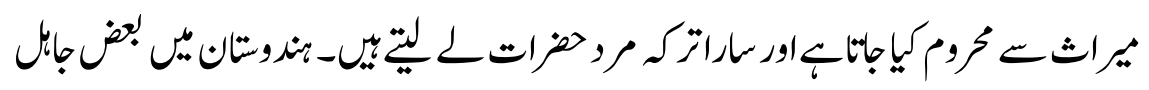

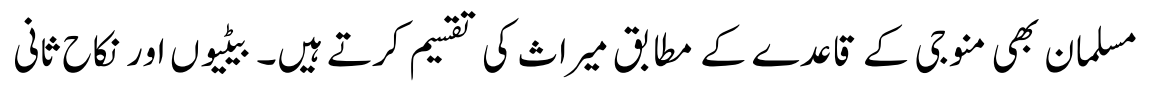
كرن وبزنانوجإبليت

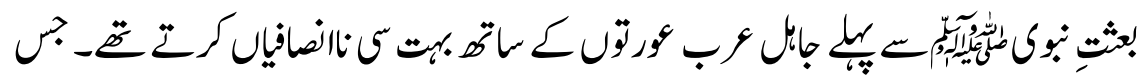

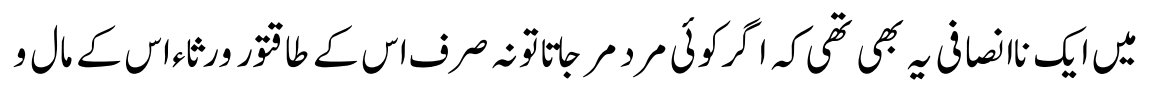

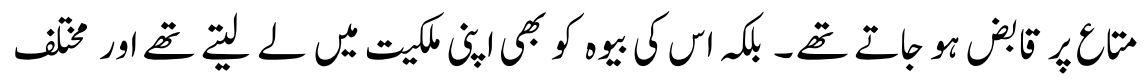

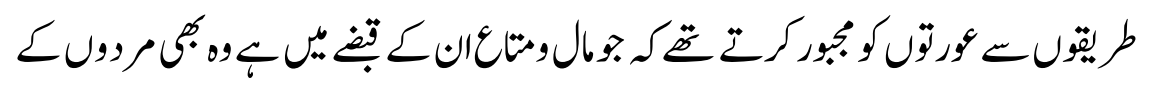




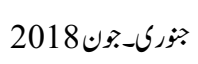

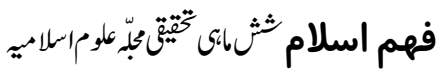

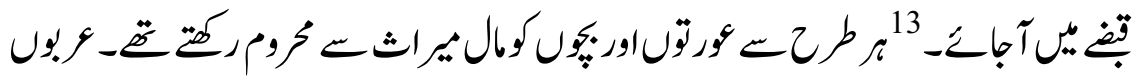

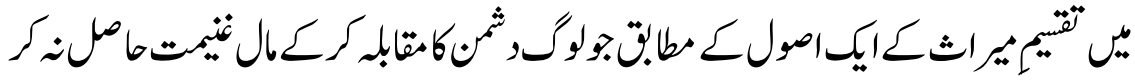

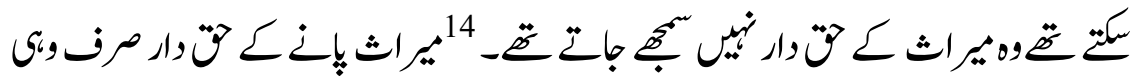

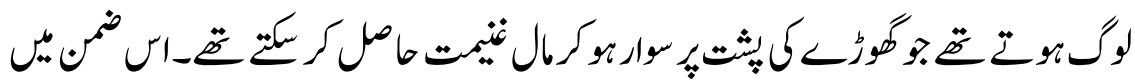

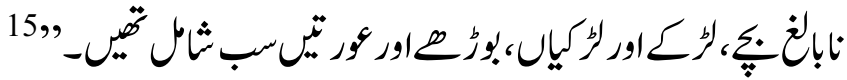

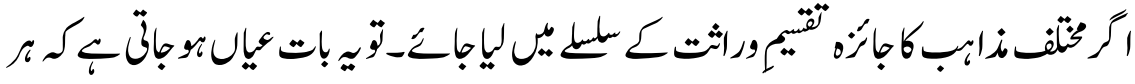

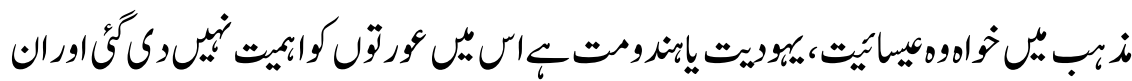

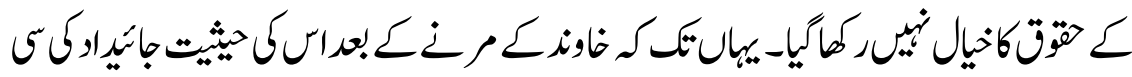

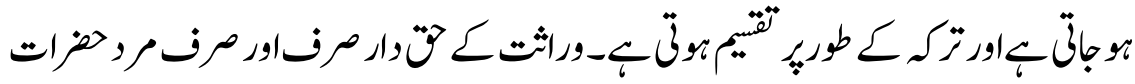

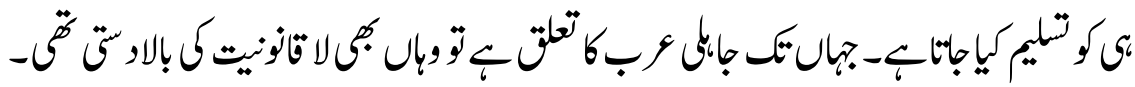

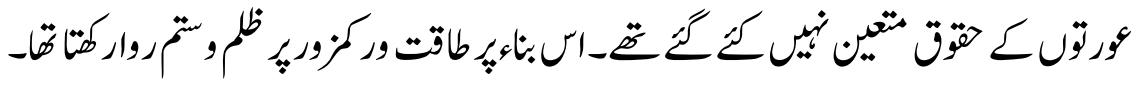

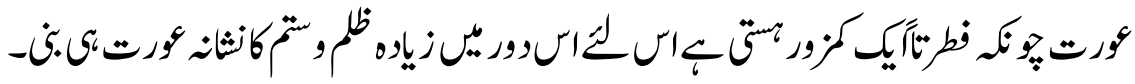

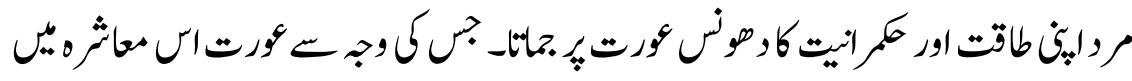

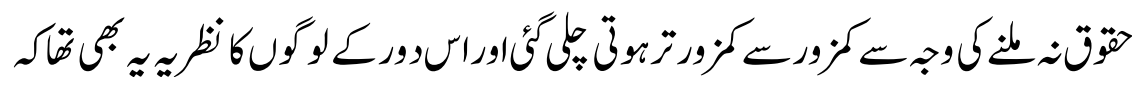

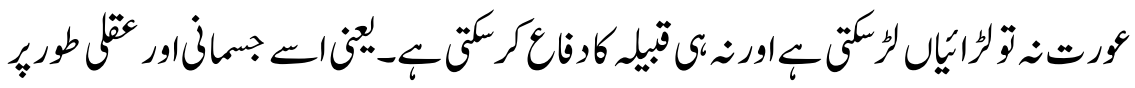

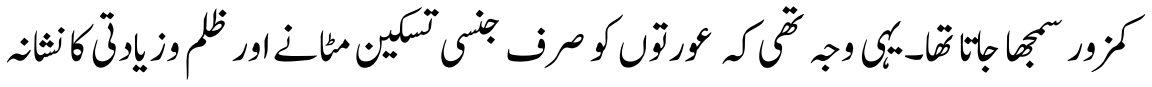

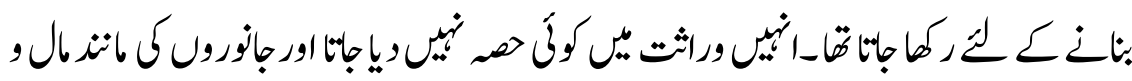

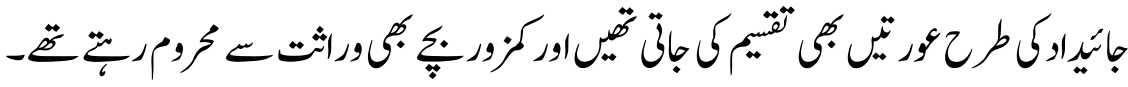

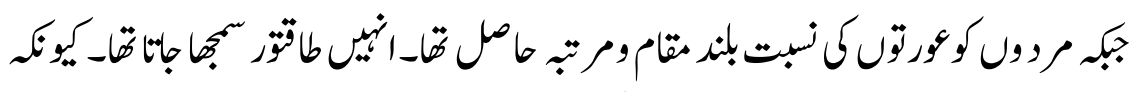

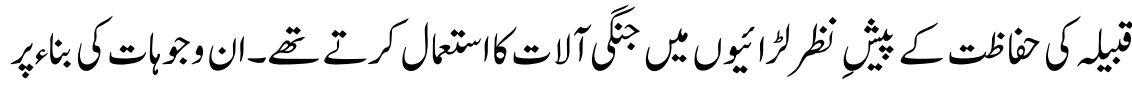

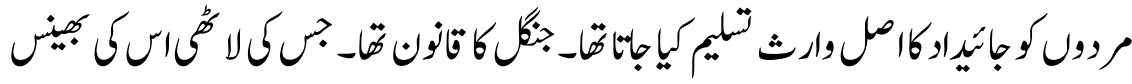

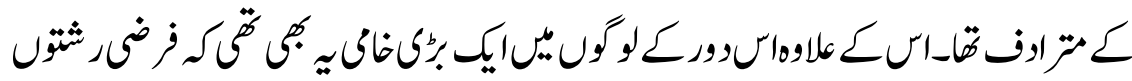

4 


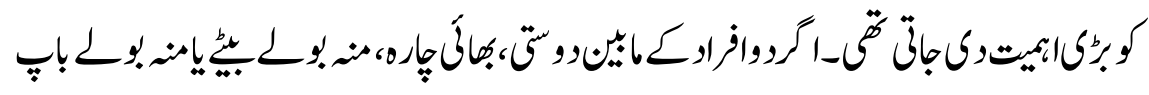

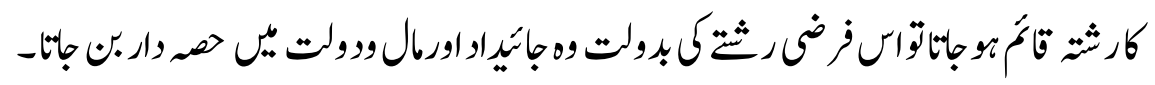

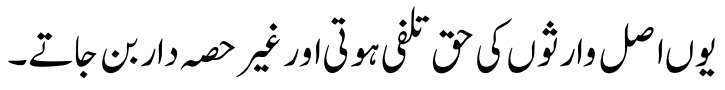

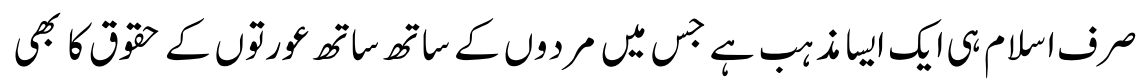

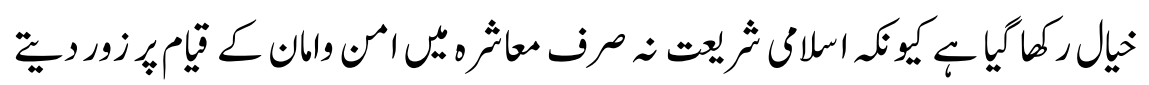

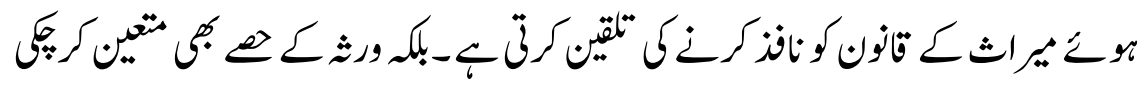

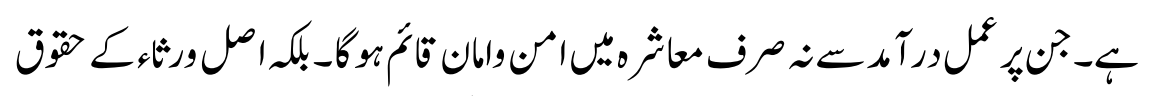

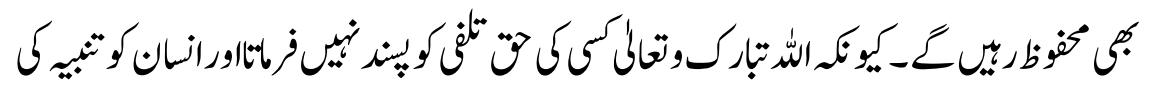

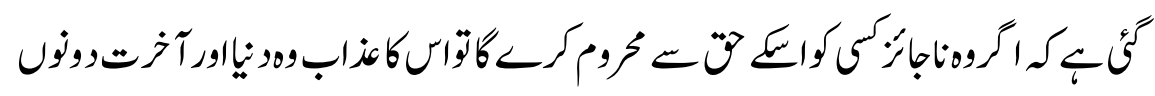
"ي -

\section{ترآناوريراث}

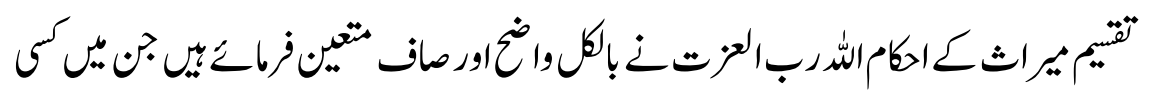

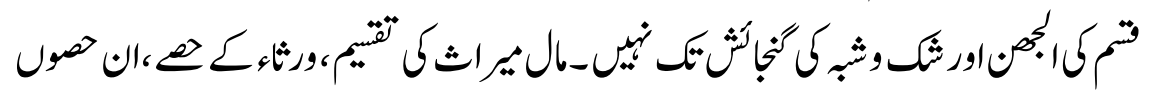

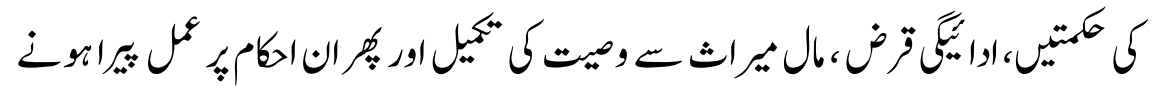

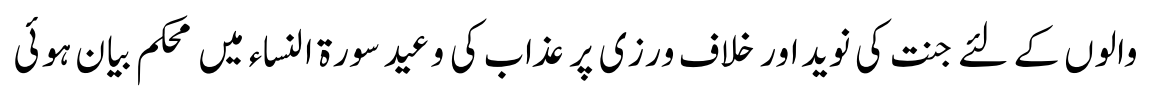

$-4$

ارثارباركتقالكَ

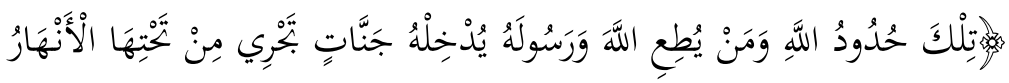

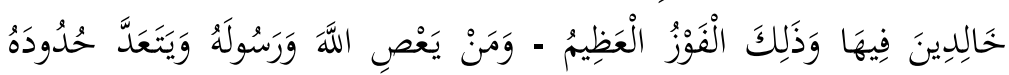

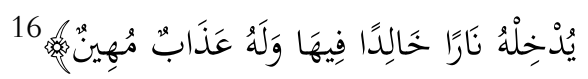

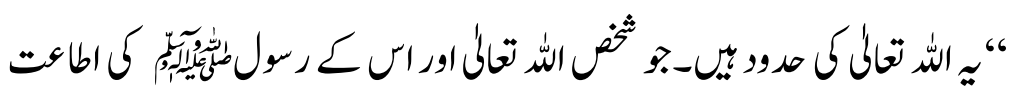

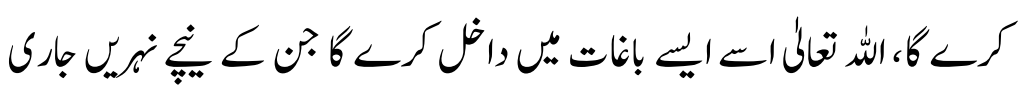

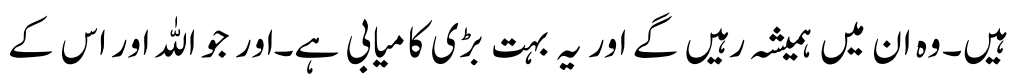




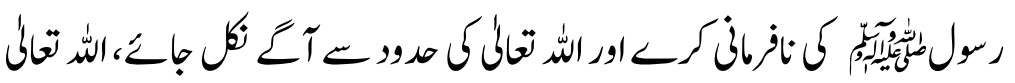

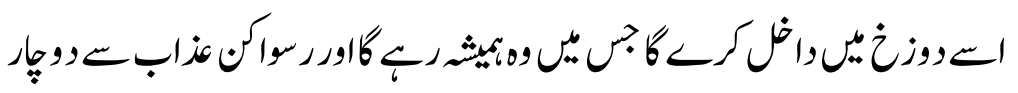
"

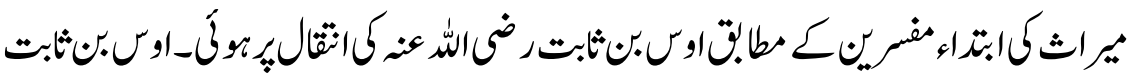

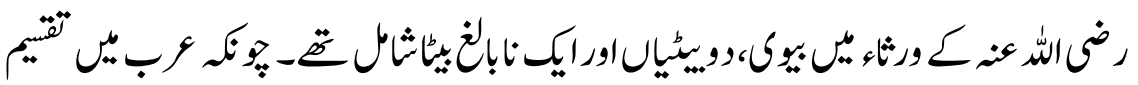

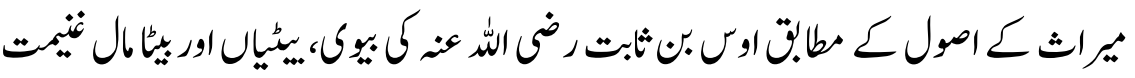

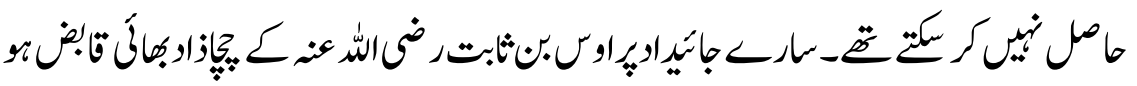

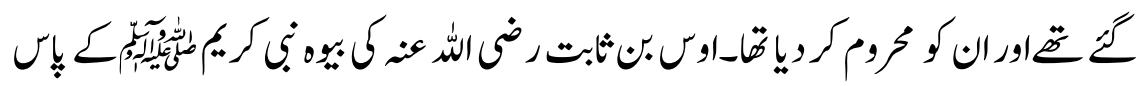

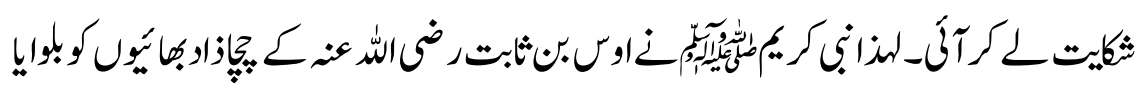

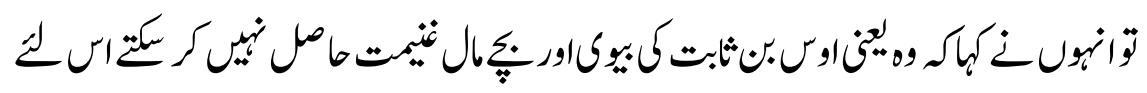

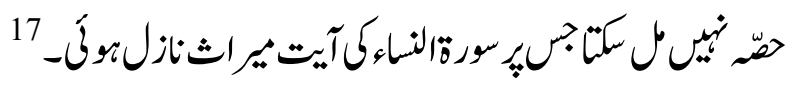

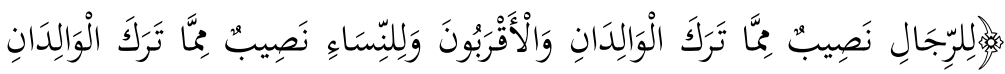

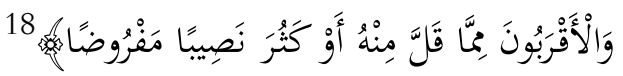

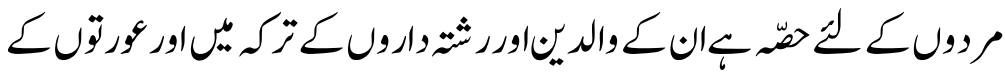

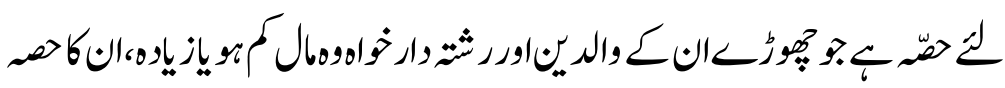
مقر كيانوابخ

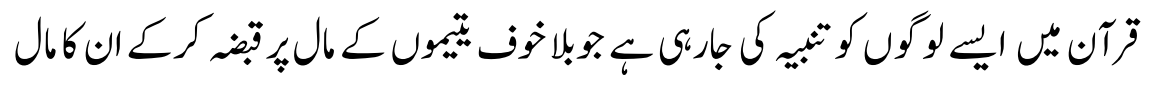

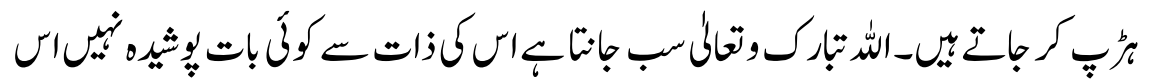

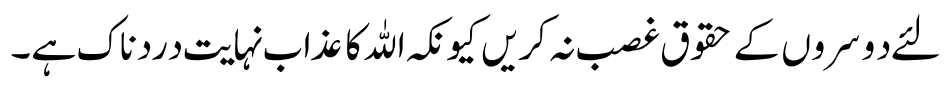

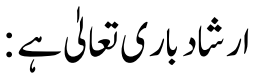

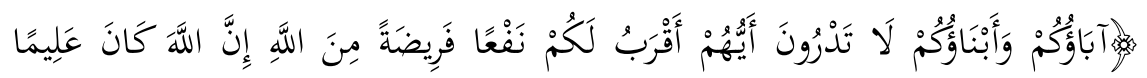

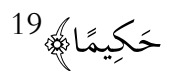




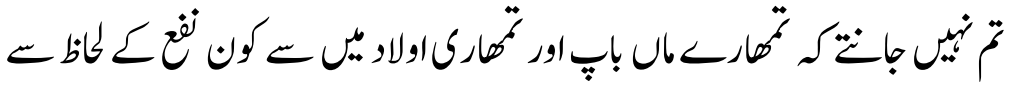

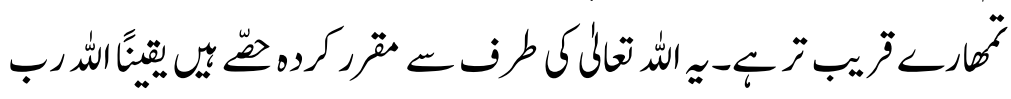

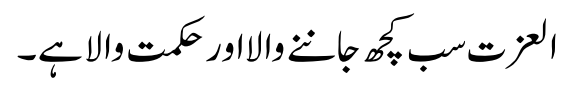

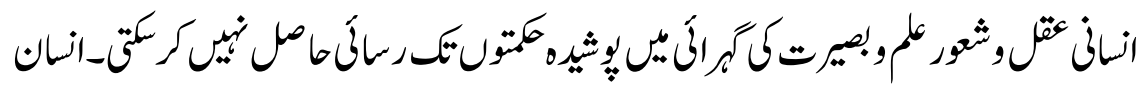

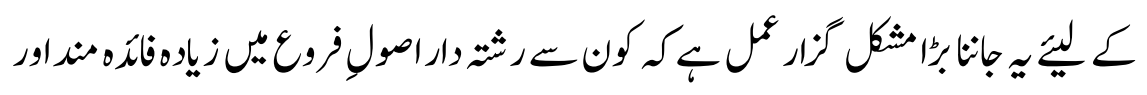

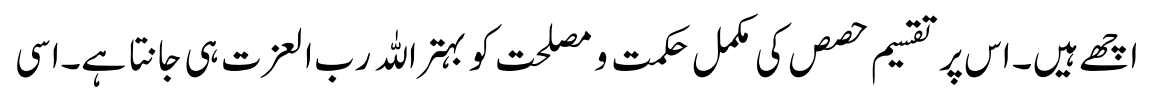

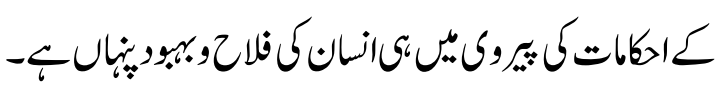

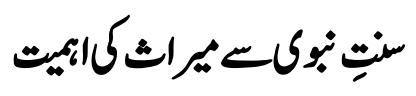

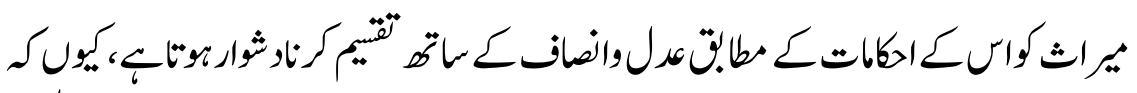

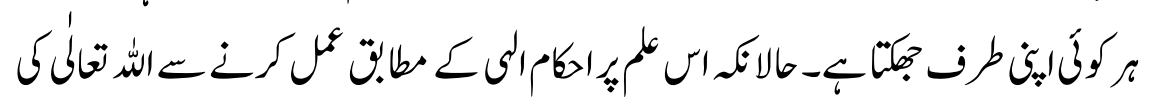

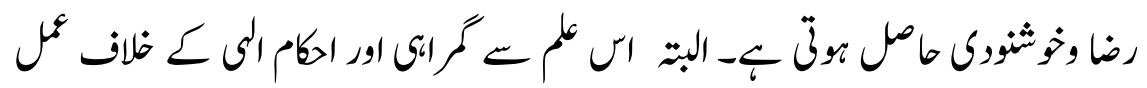

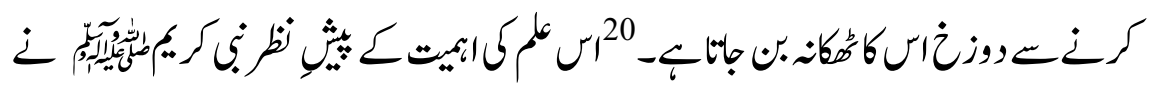

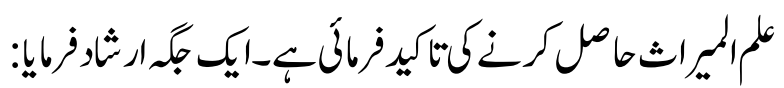

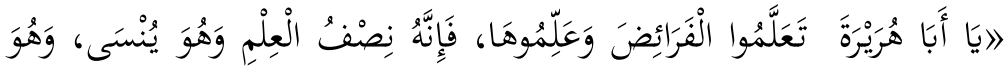

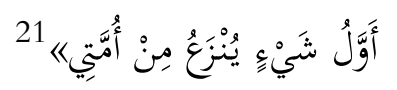

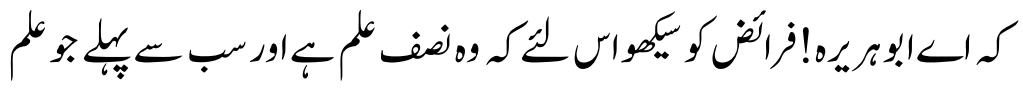

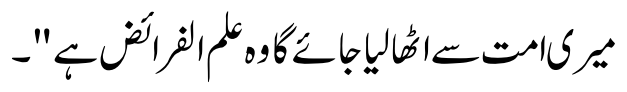

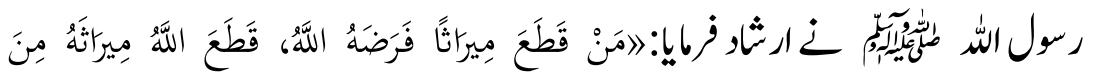

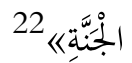

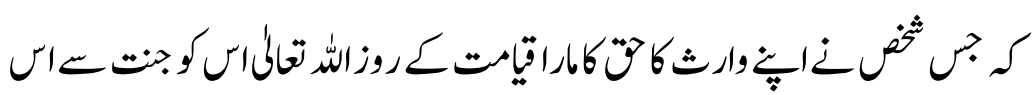

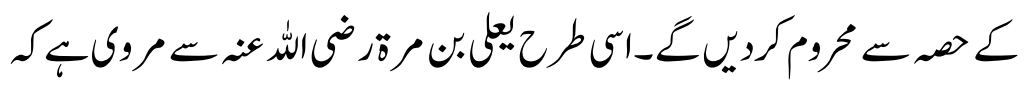

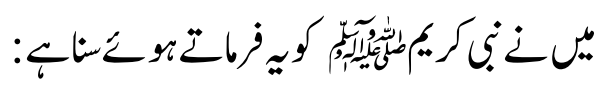




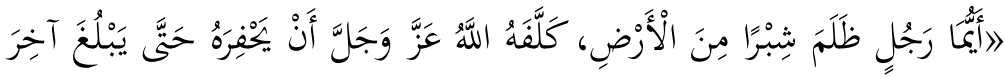

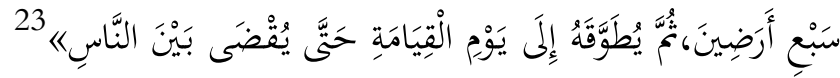

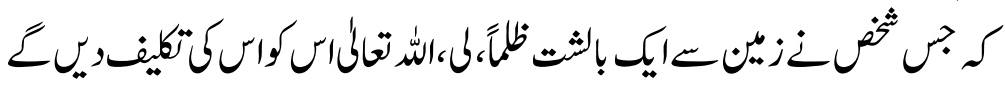

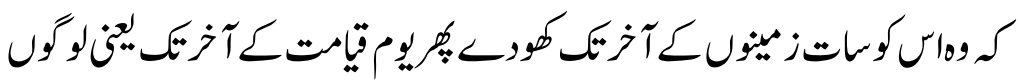

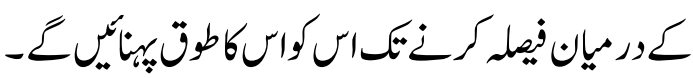

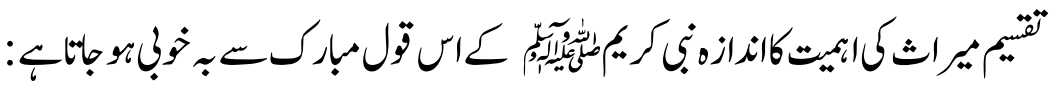

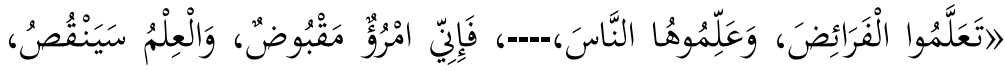

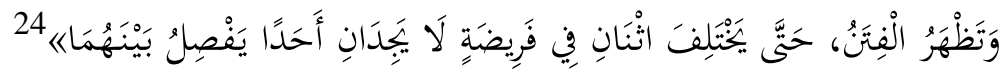

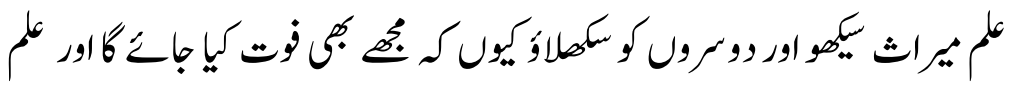

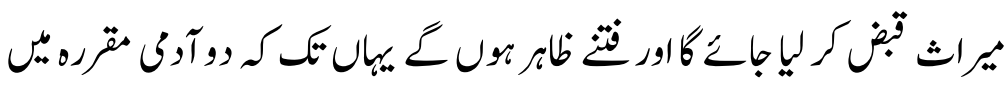

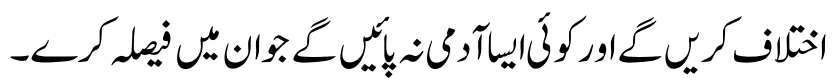

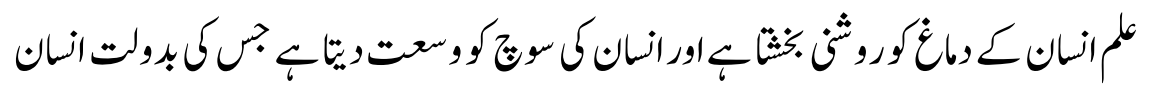

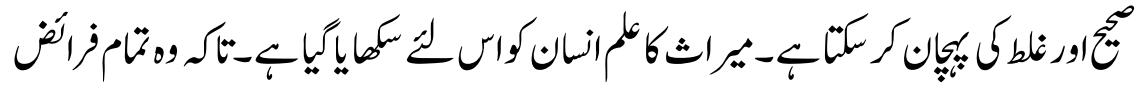

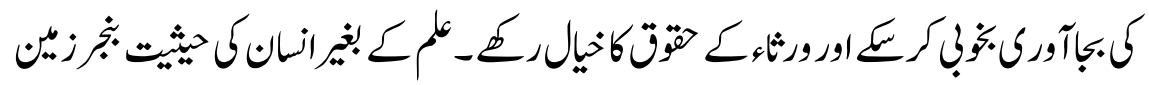

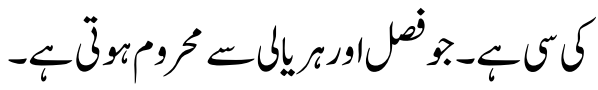

$$
\begin{aligned}
& \text { ميراثكايميت صحاب كرام نزويك }
\end{aligned}
$$

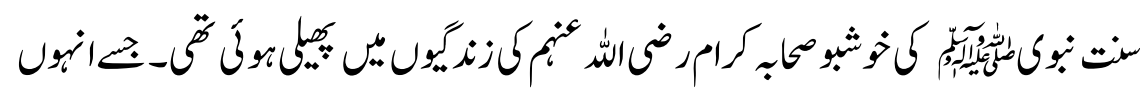

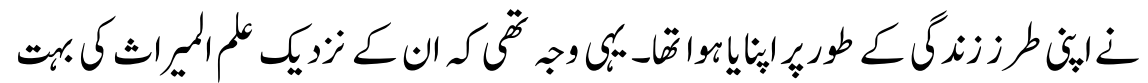

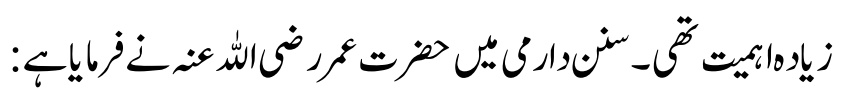

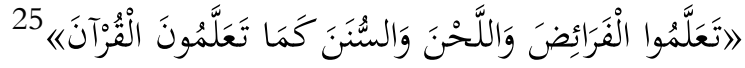

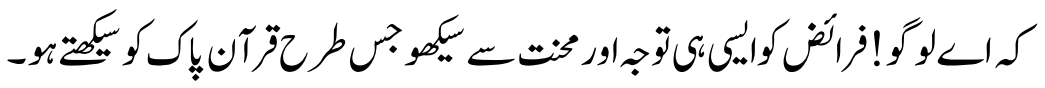

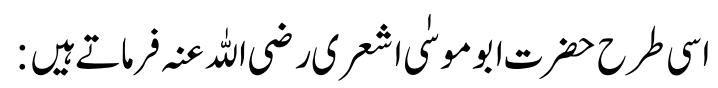




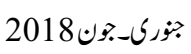

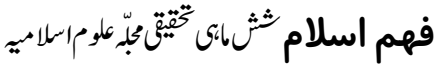

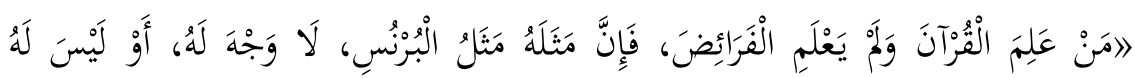

وَجْجُهُ 26

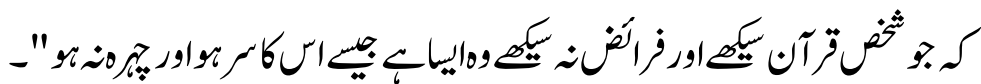

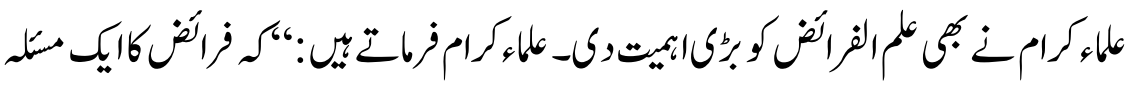

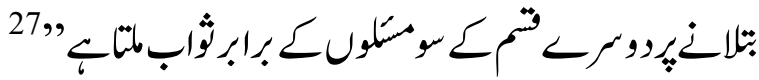

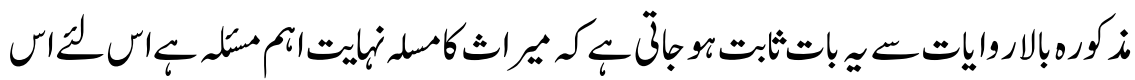

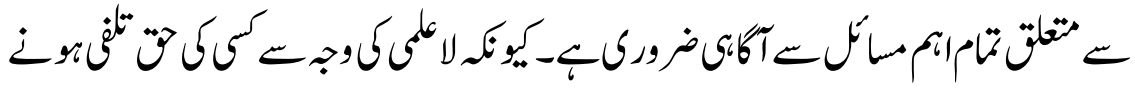

كامكان-

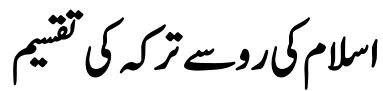

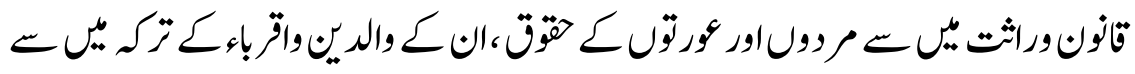

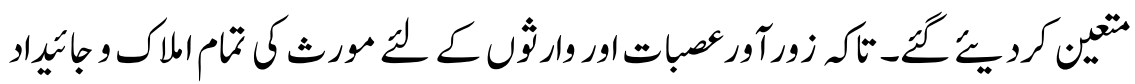

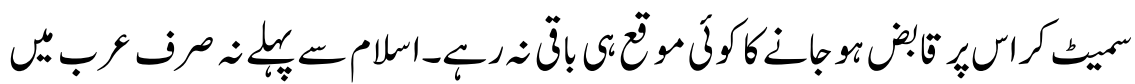

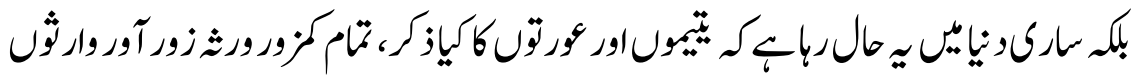

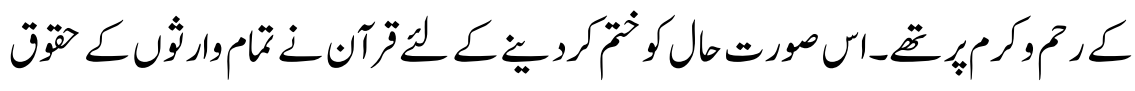

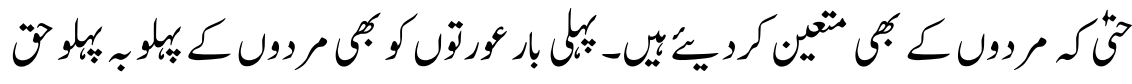

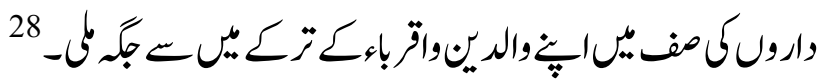

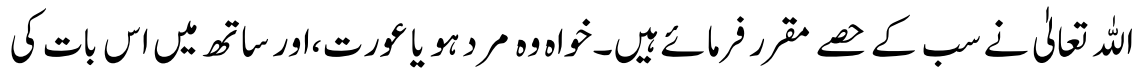

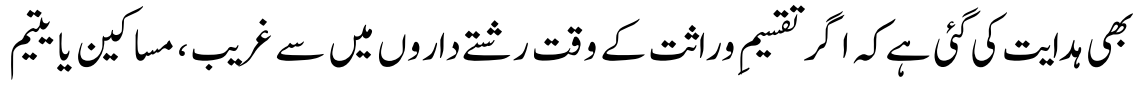

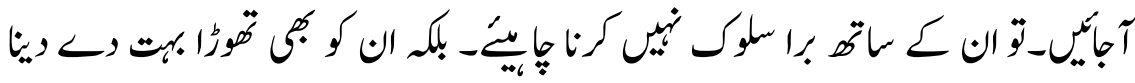

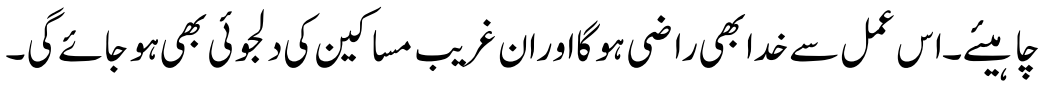

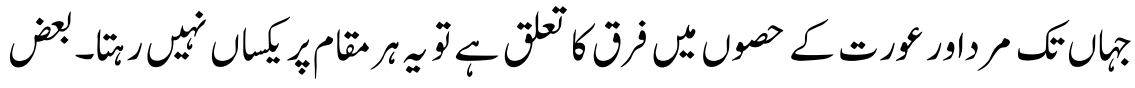

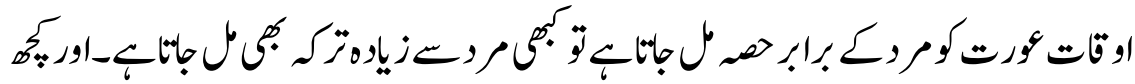

9 


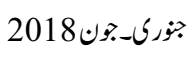

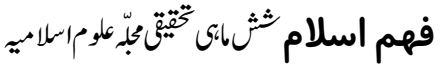

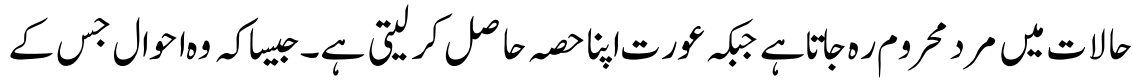

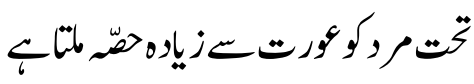

ميكالت

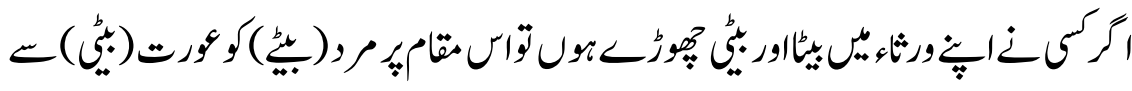

,

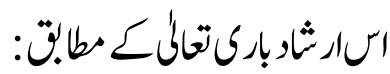

29 29

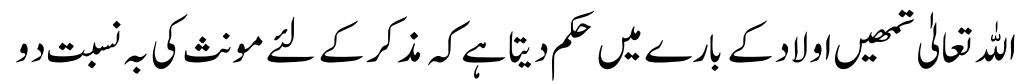

-

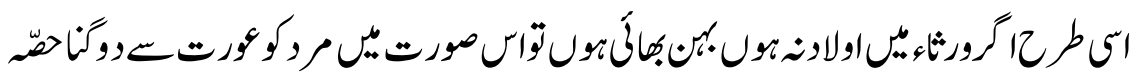

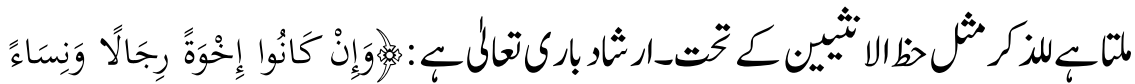

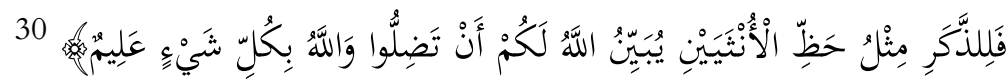

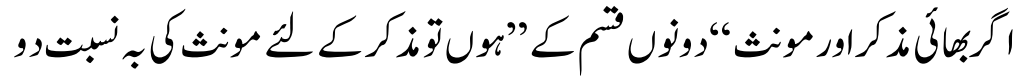

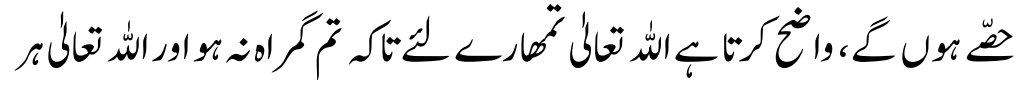

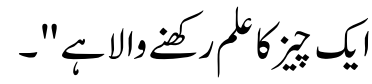

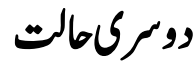

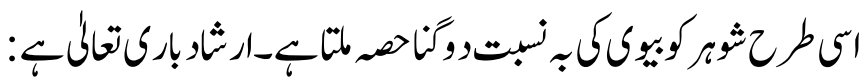

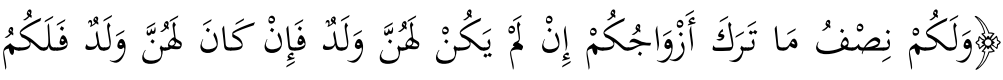

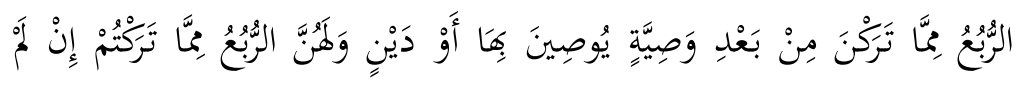

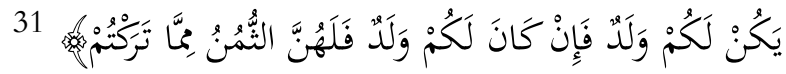

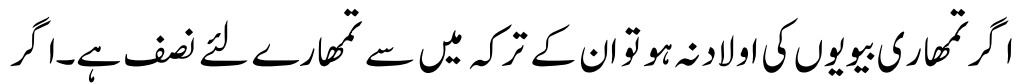

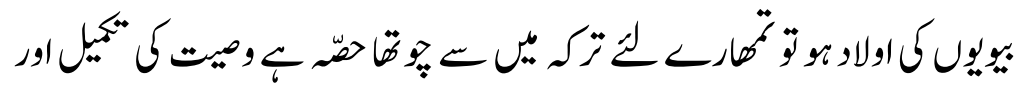

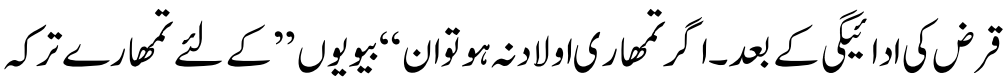

10 


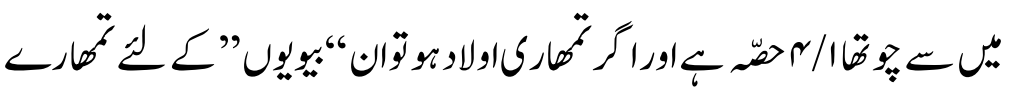

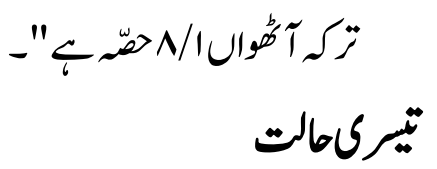

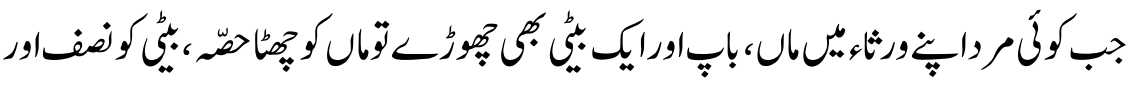

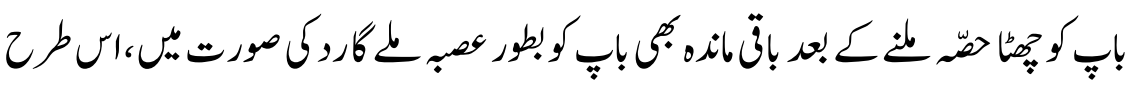

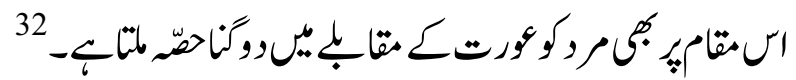

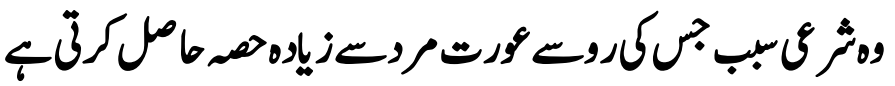
تمبكامالت

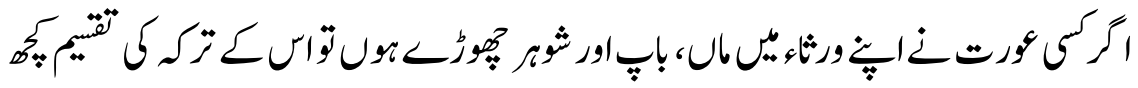

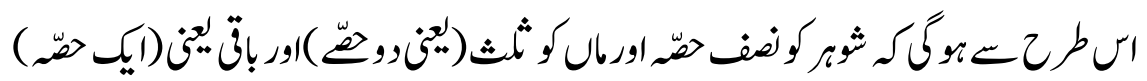

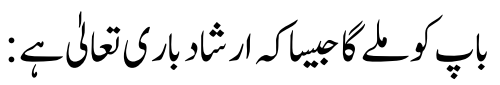

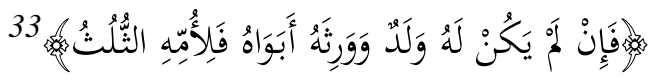

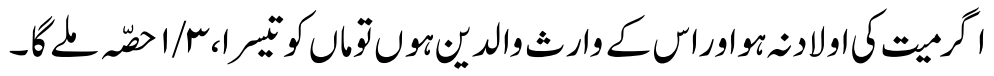

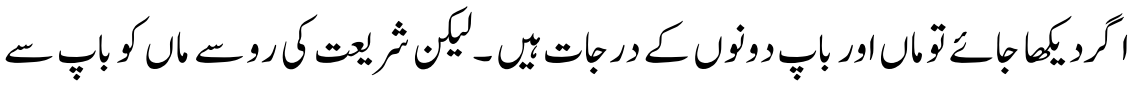

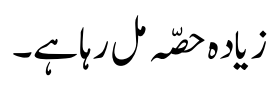

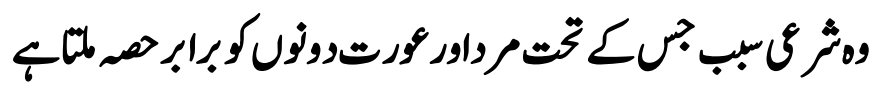

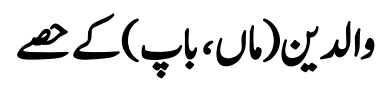

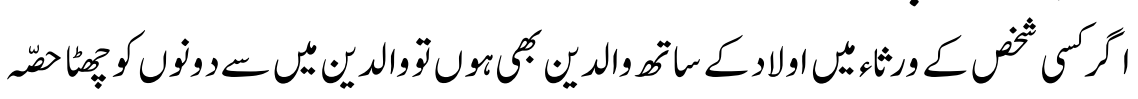

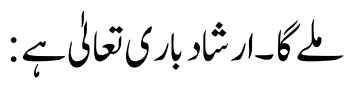

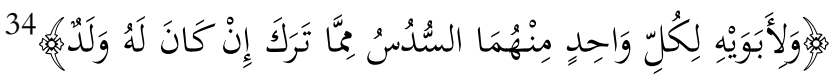

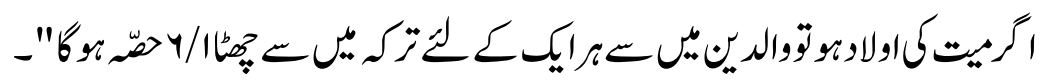




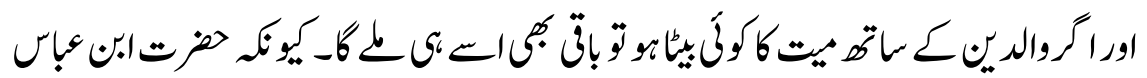

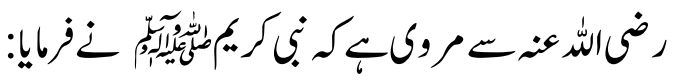

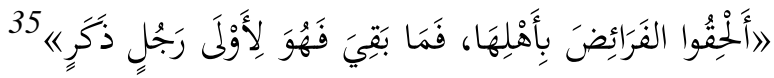

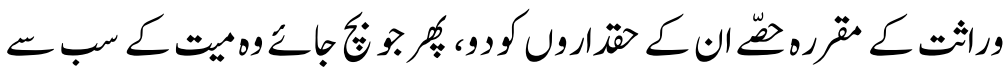

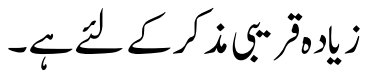

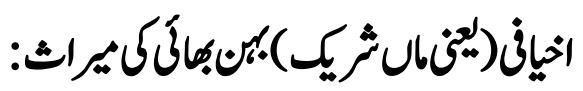
كالركتريف

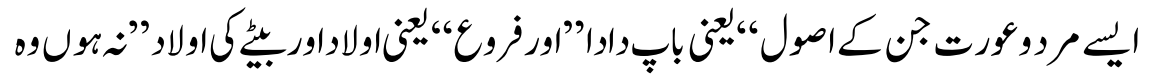

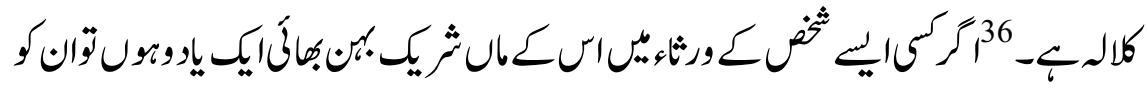

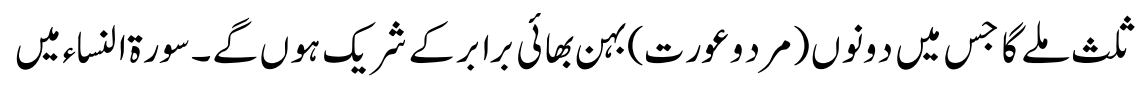

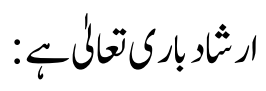

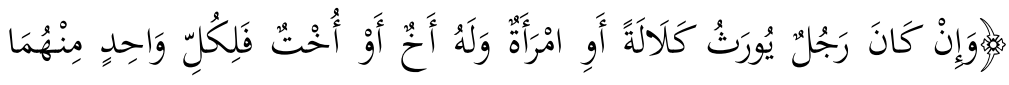

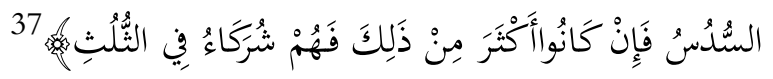

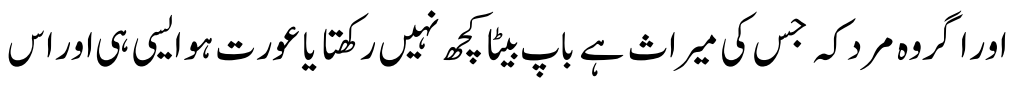

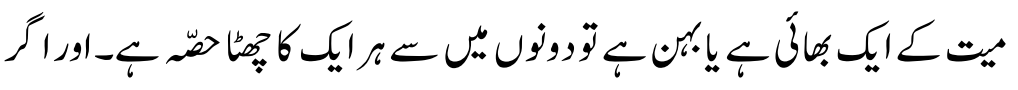

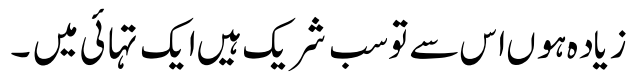
وجوإتثاوت

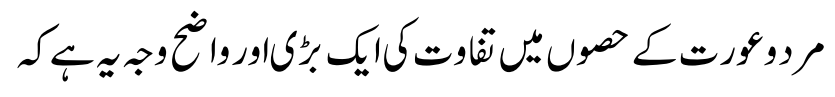

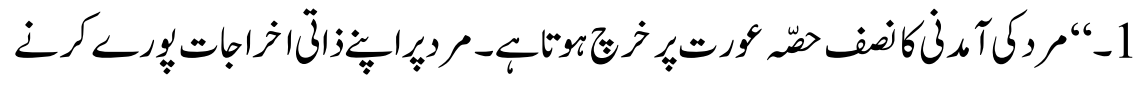

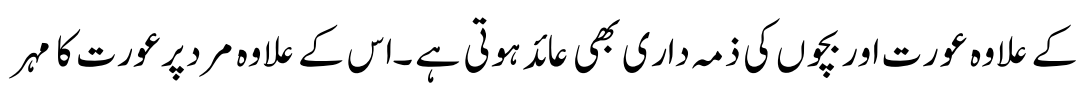

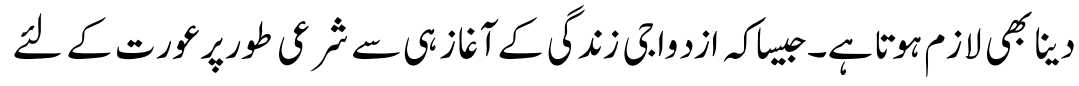

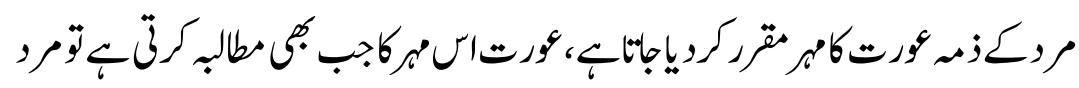




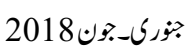

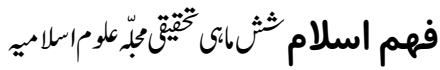

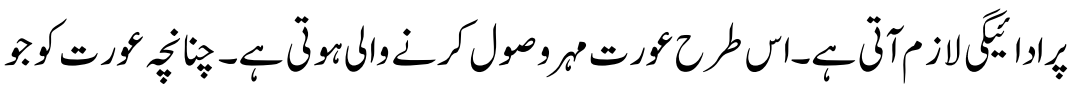

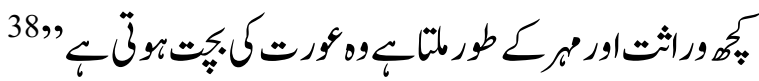

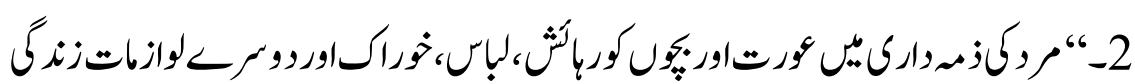

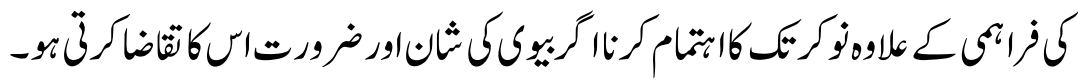

${ }^{39}-40$

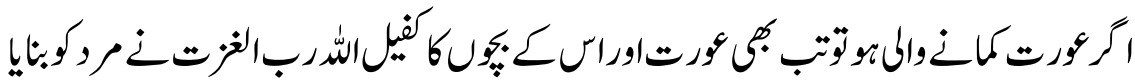

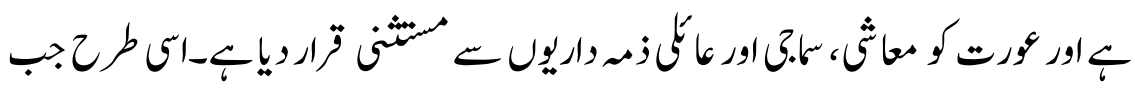

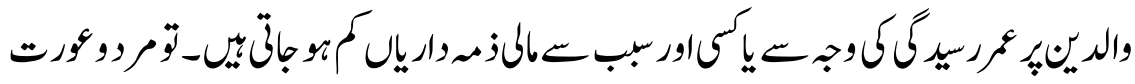

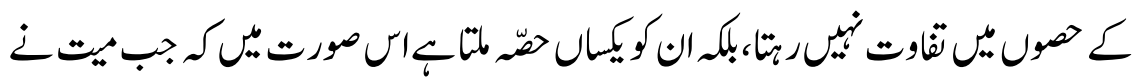

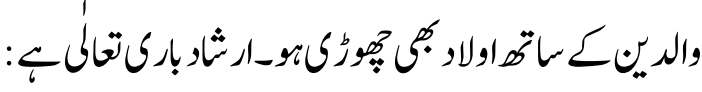
40.

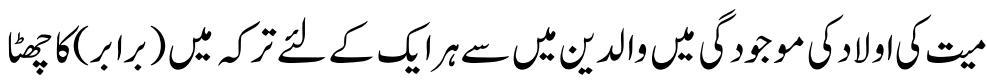

$-\frac{1}{4}$

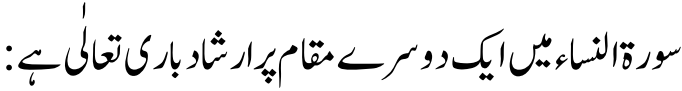

مانِ

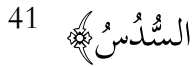

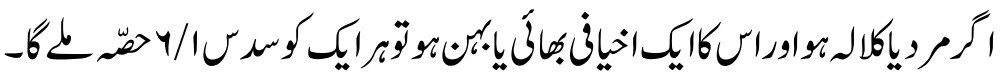

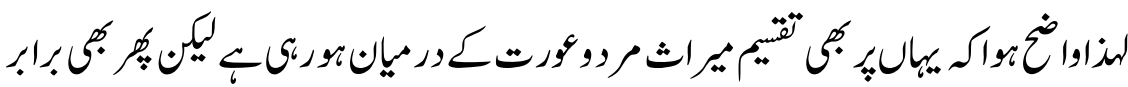

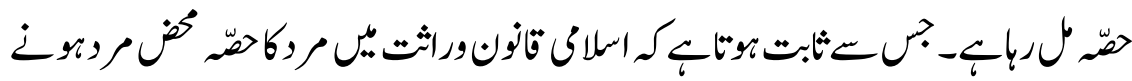

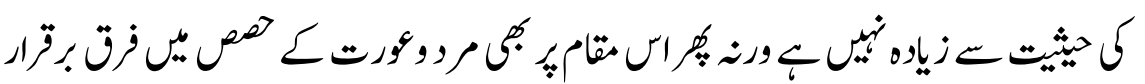

42 ,

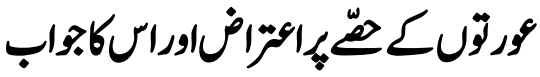

13 


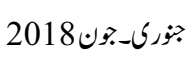

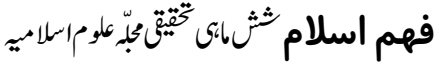

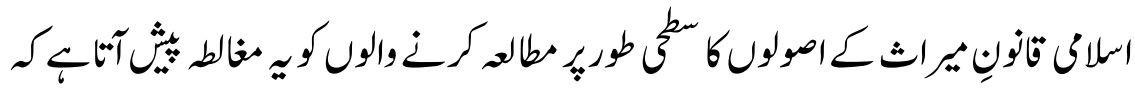

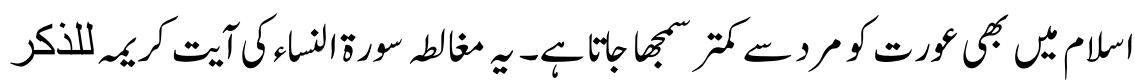

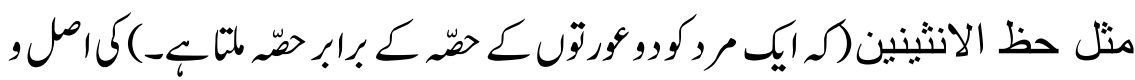

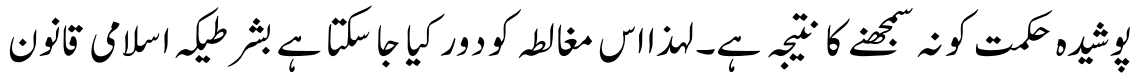

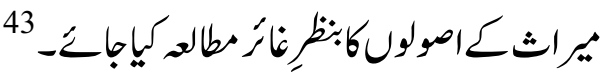

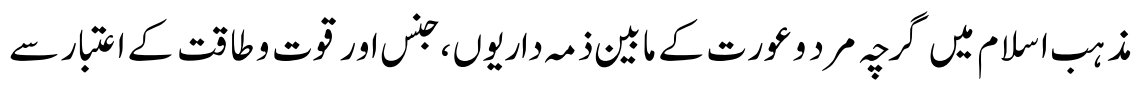

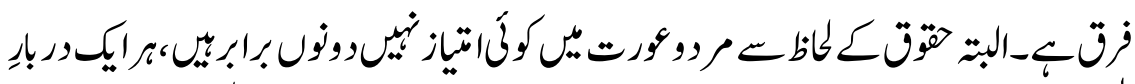

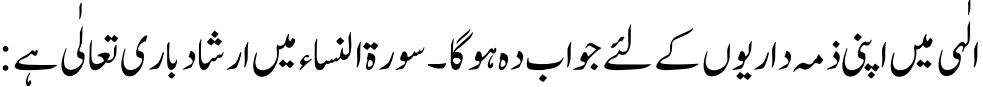

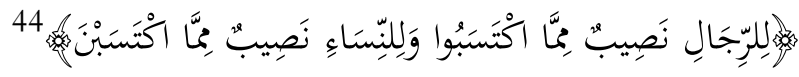

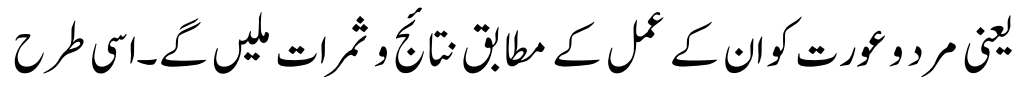

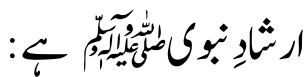

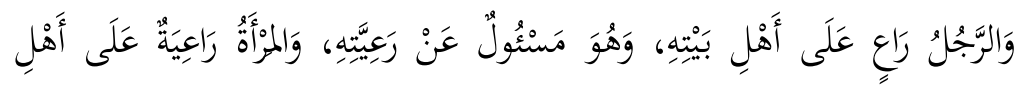

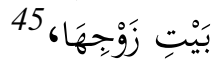

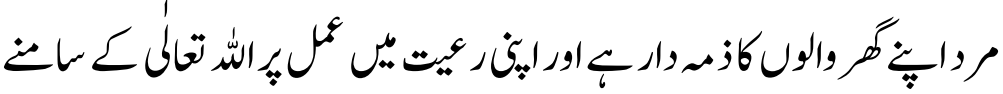

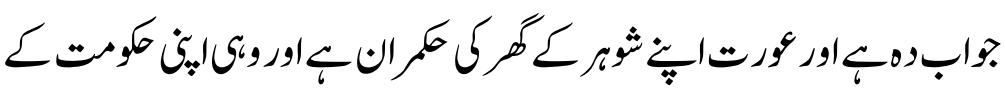

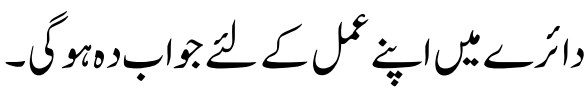

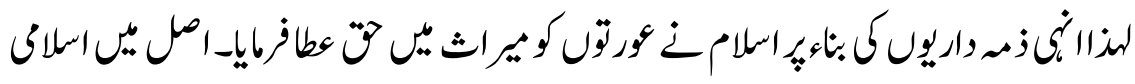

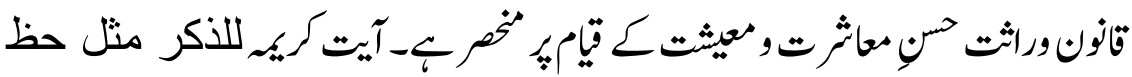

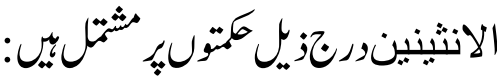

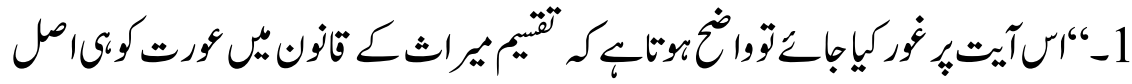

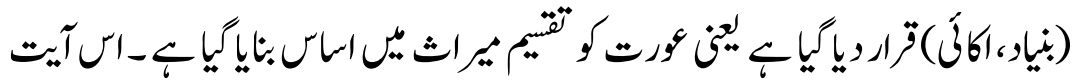

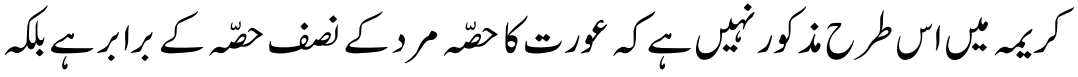

14 


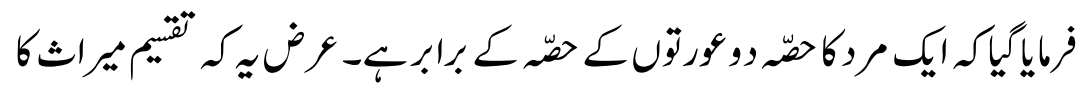

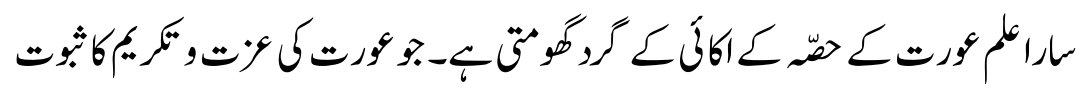
$" \leftarrow$

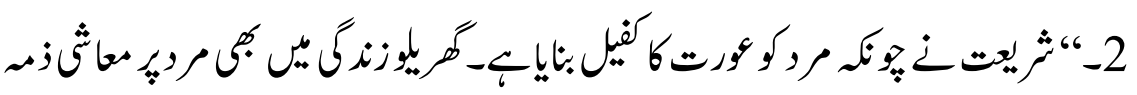

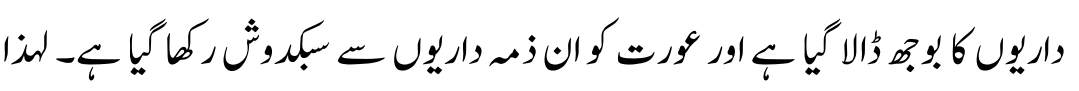

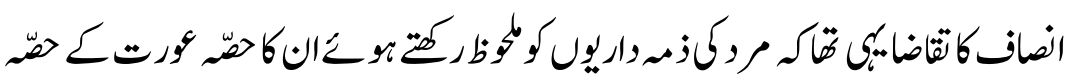

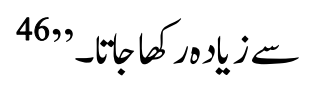

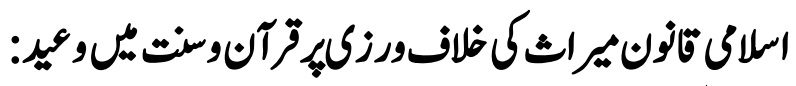

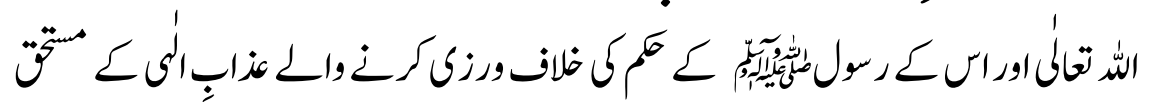

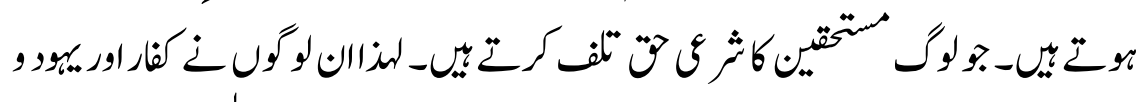

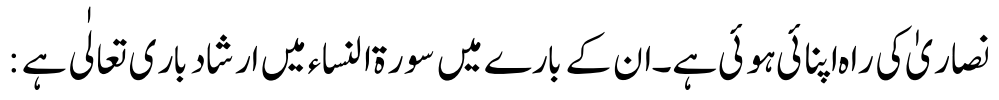

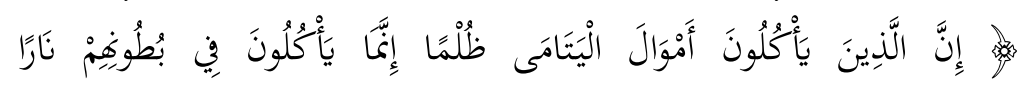

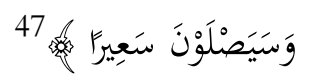

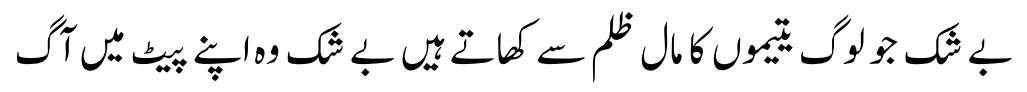

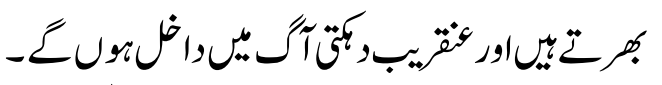

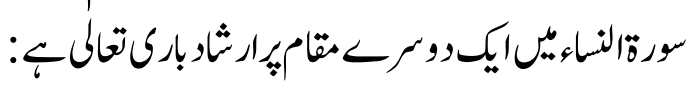

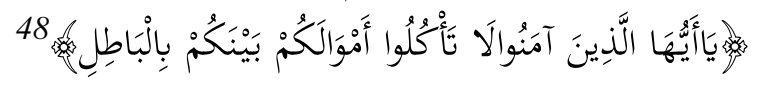

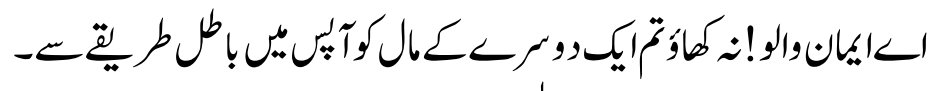

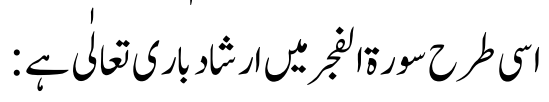

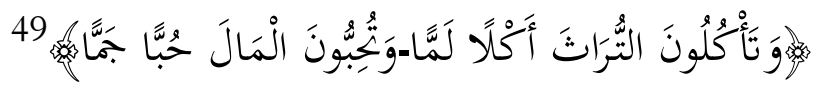

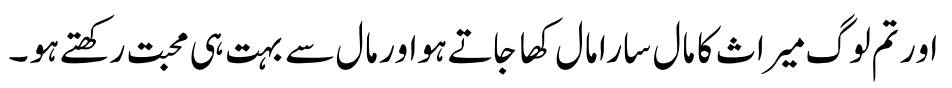




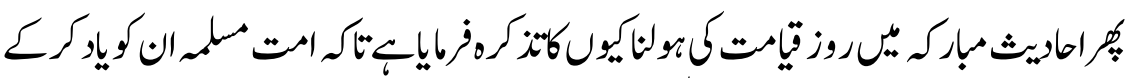

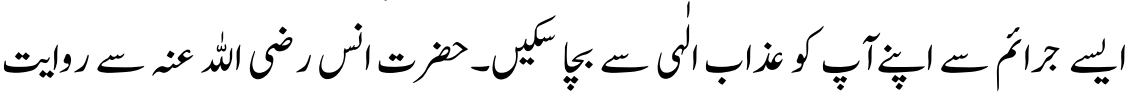

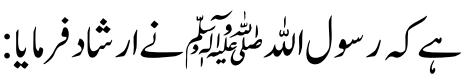

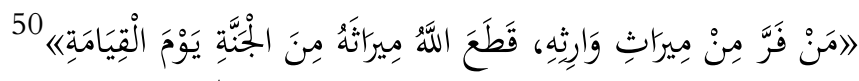

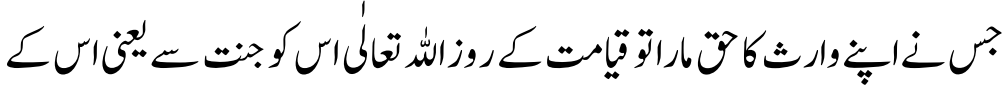

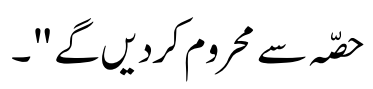

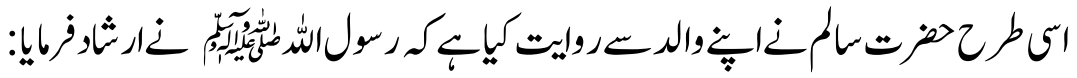

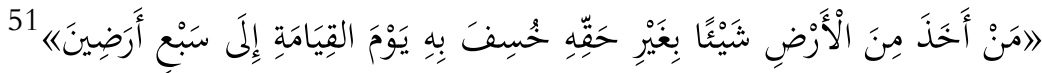

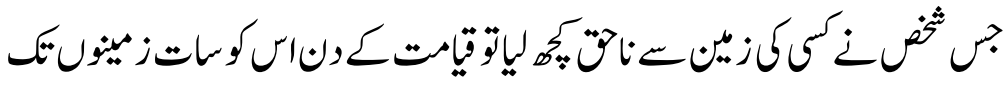

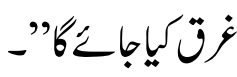
تضميم تميراشع فوائ

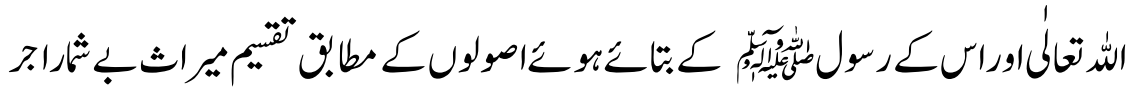

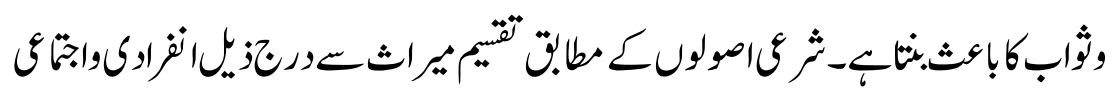
فواركاصلمتحتين:

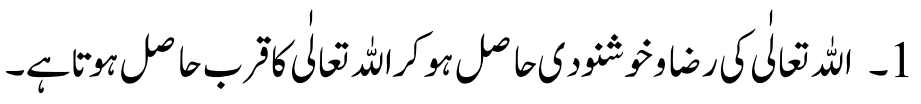

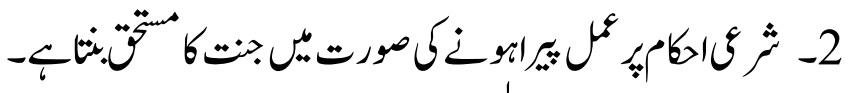

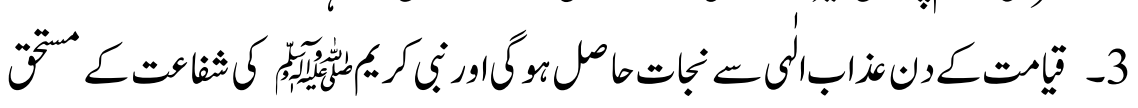

\section{EU}

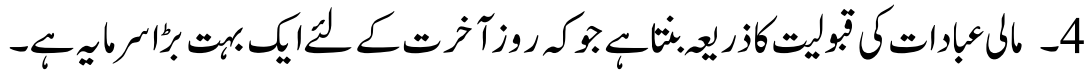

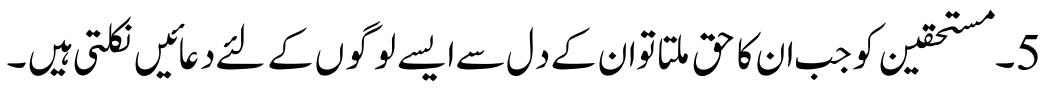

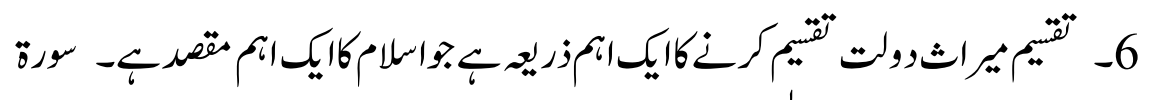

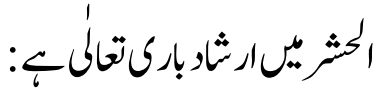




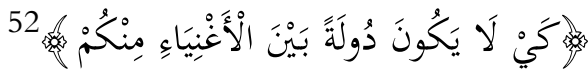

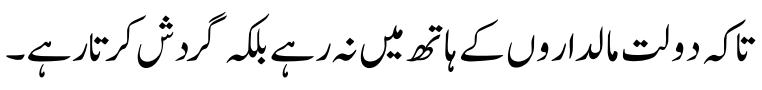

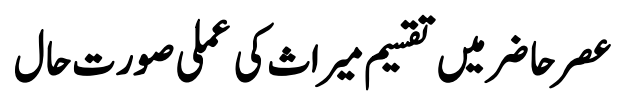

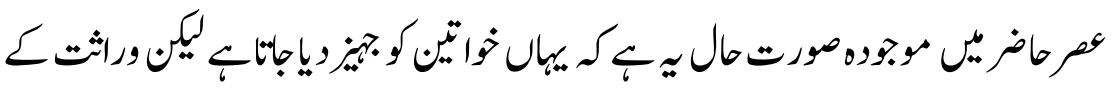

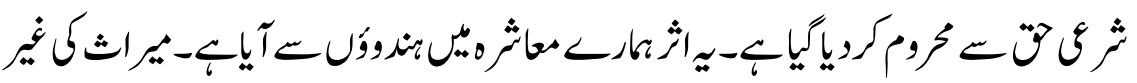

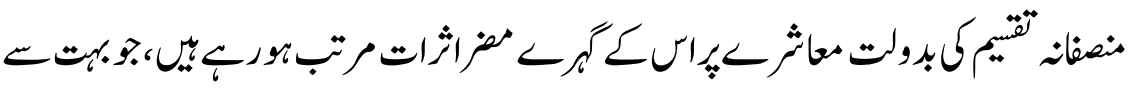

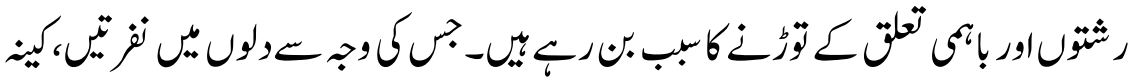

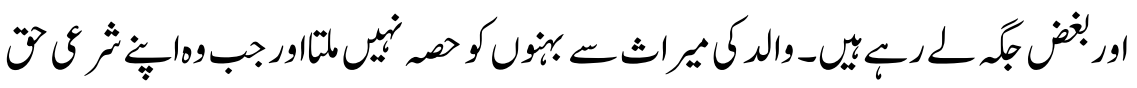

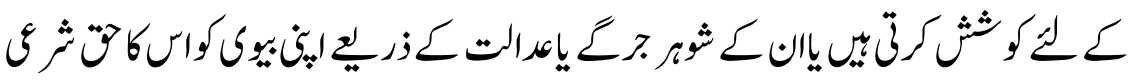

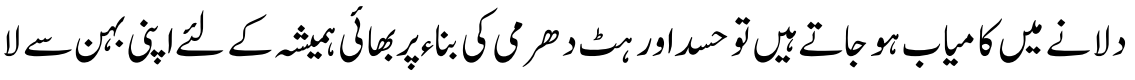

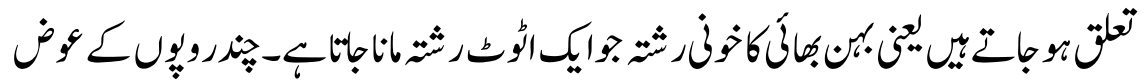

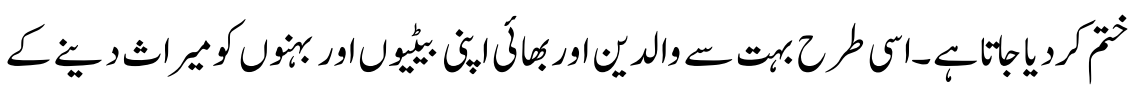

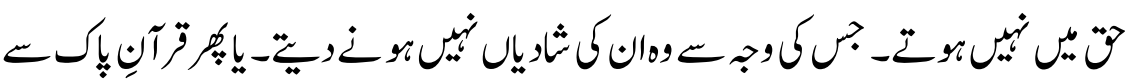

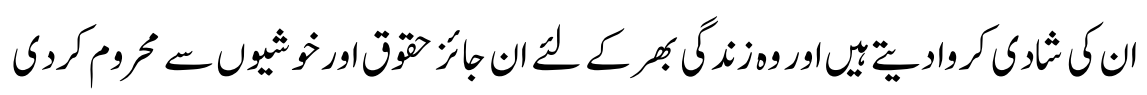

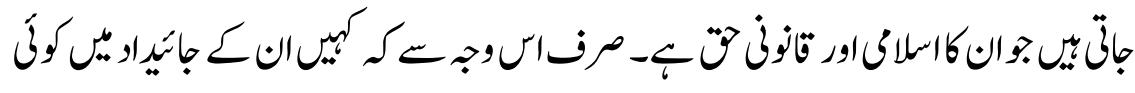

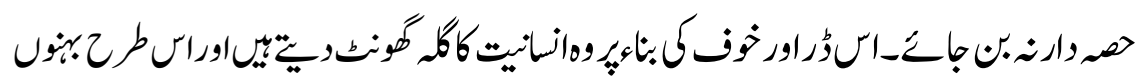

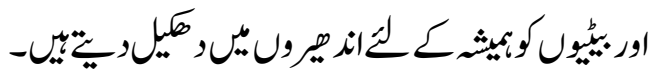

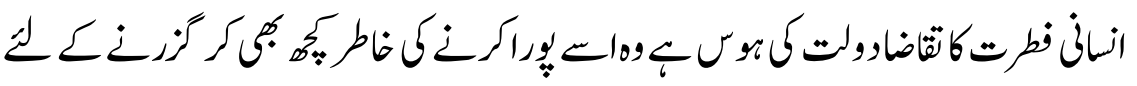

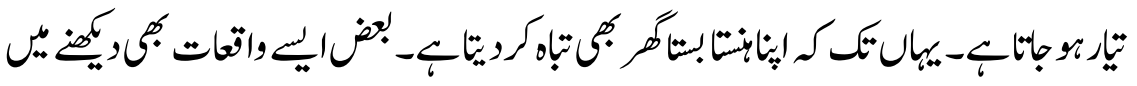

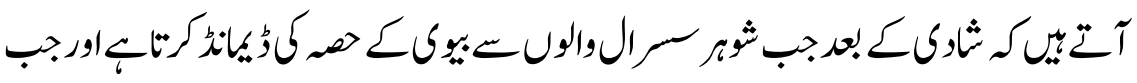

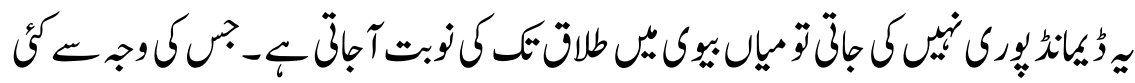

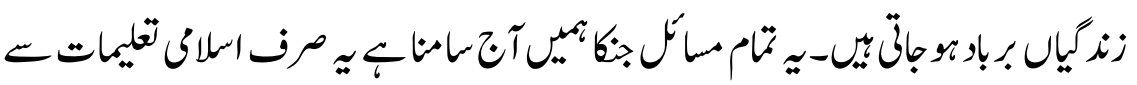




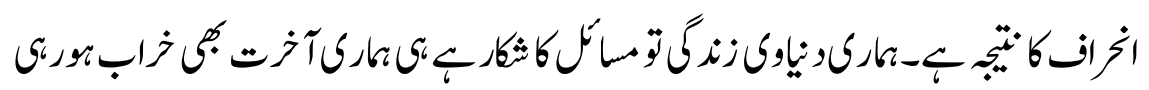

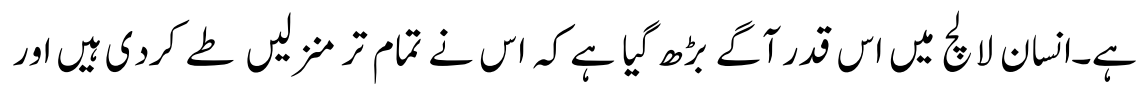

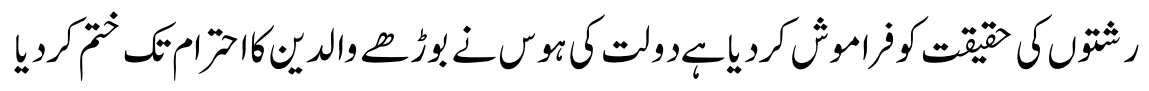

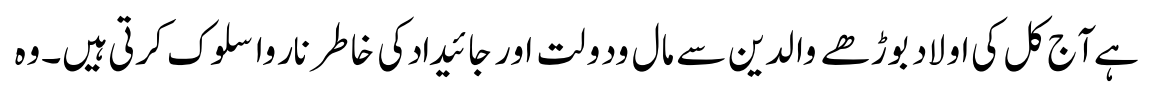

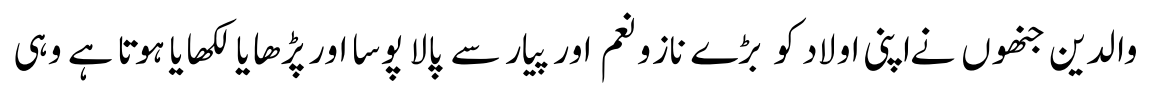

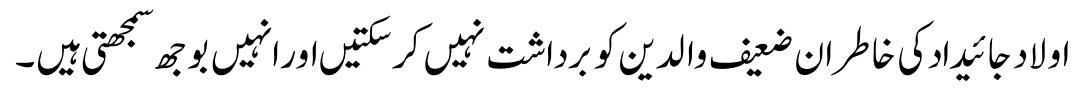

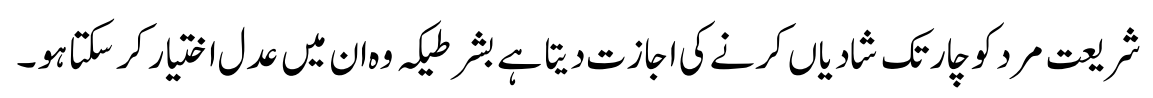

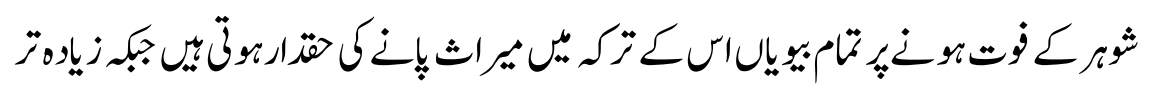

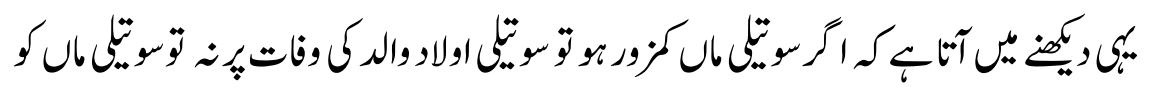

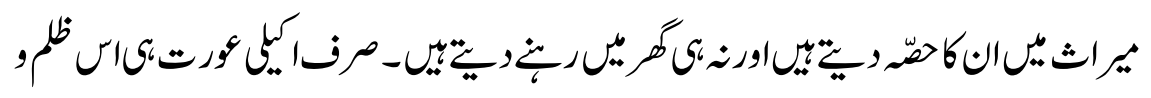

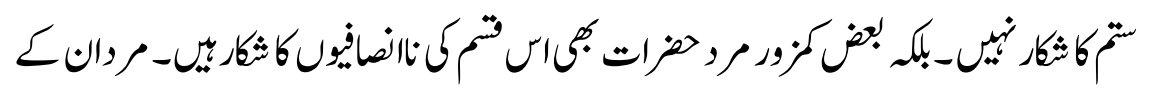

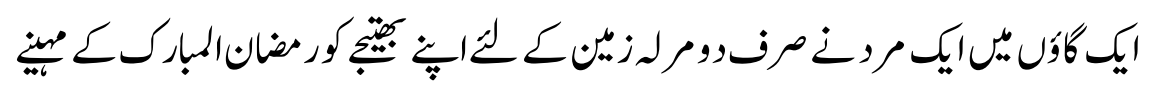

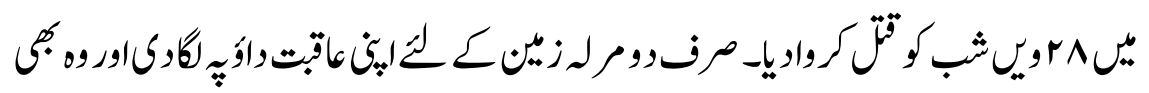
رمضان المباركس عبابركت مينّي"

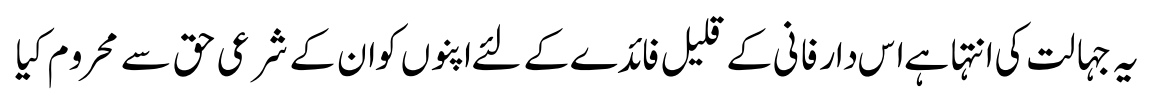

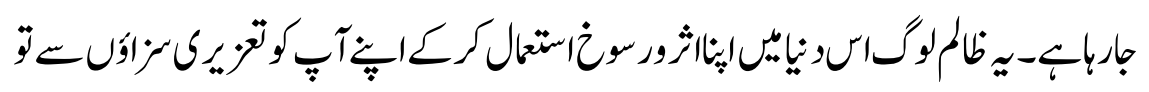

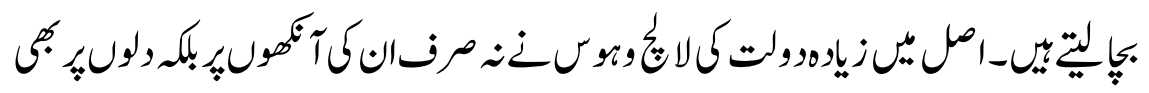

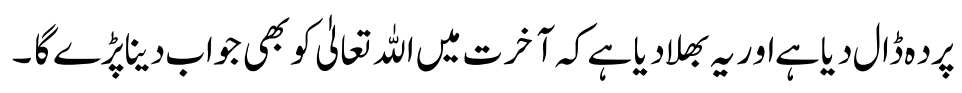

خلام.كث

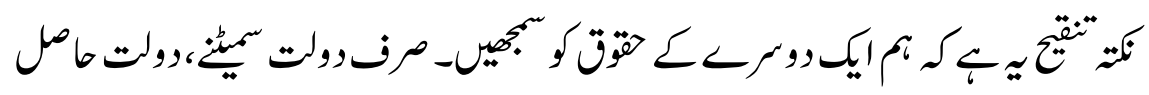

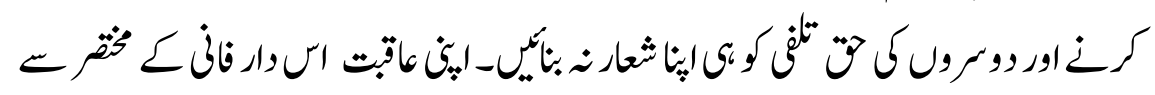




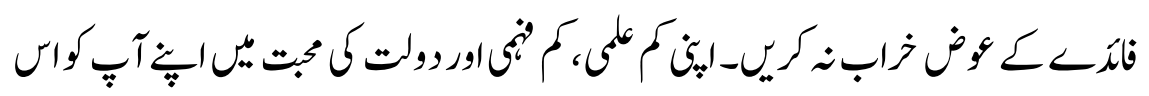

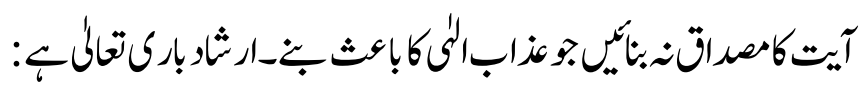

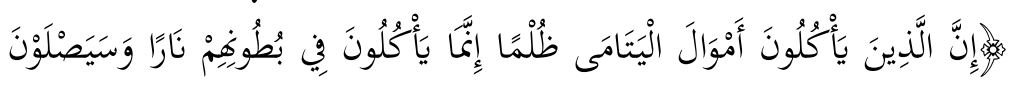

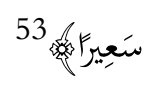

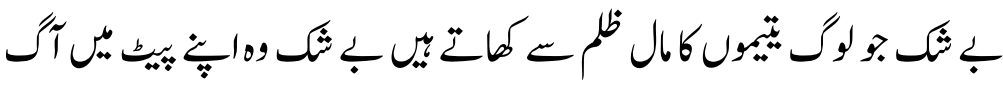

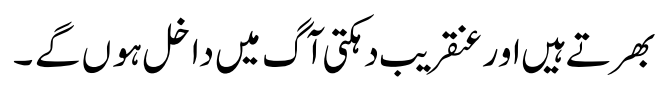

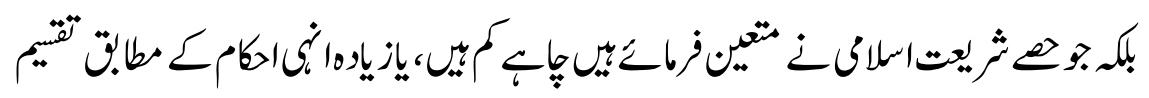

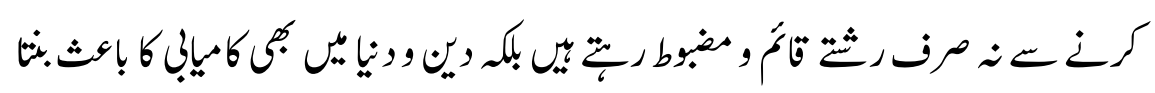

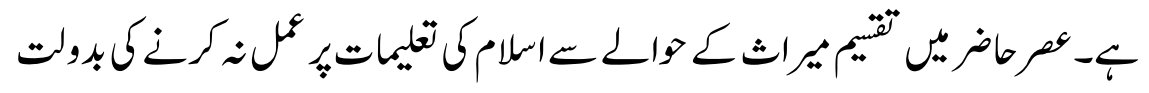

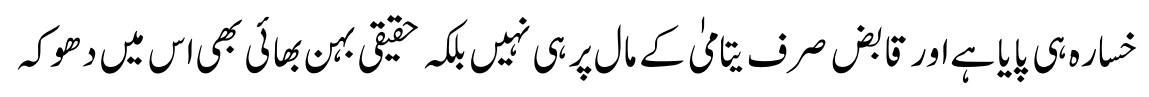

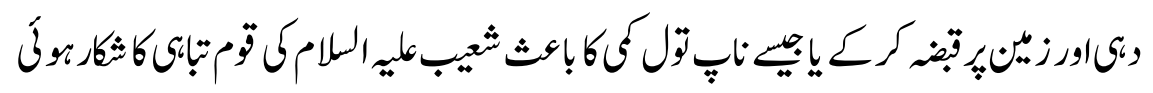

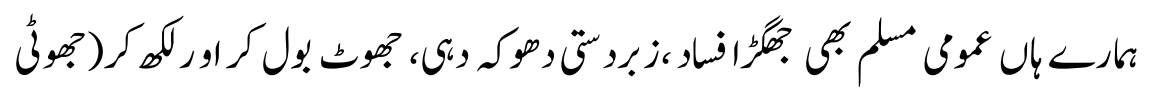

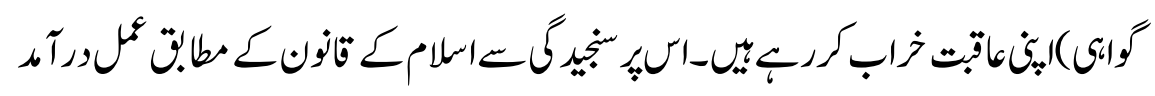

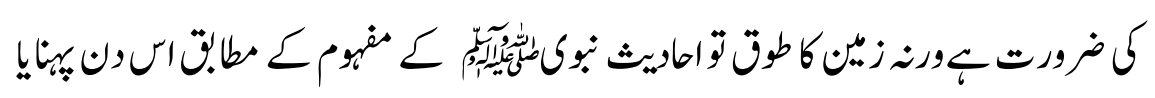
ج

والرجات

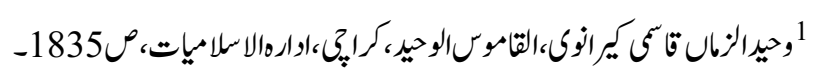

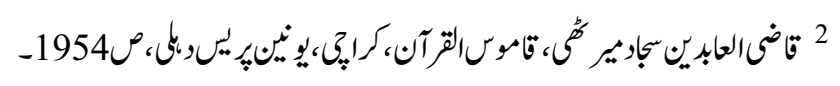

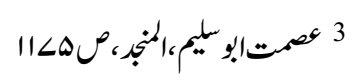

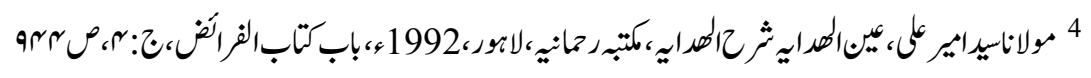

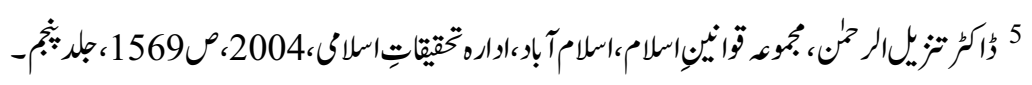

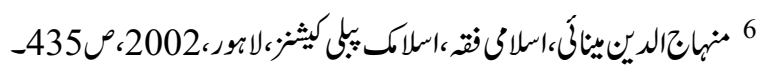




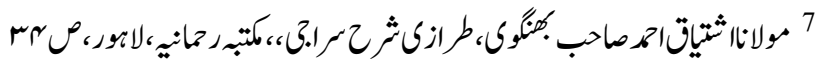

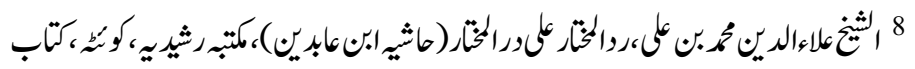

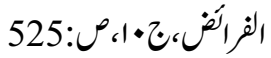

${ }^{9} \mathrm{http} / / /$ www.ehow.com/facts_6772911_jewish-law-concerninginheritance_html(11,12,13)

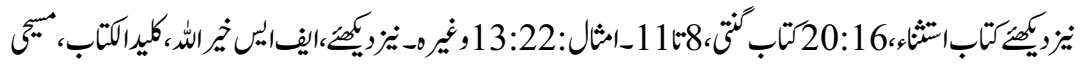

$$
\begin{aligned}
& \text { اشاعتخان،لانور،2007 }
\end{aligned}
$$

${ }^{10} \mathrm{http}$ ://answers.yahoo.com/question/index?qid(11,12,13).see also: Laws of Christians

11

http://www.islamweb.net/emainpage/index.php?page=articles\&id=17710 $7(11,12,13$

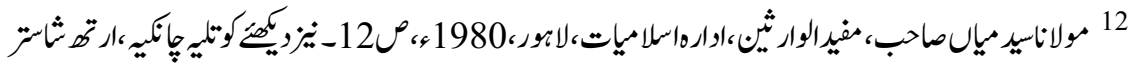

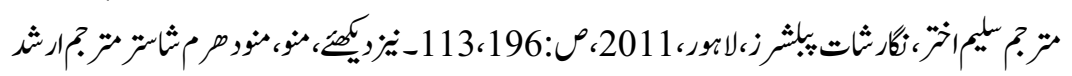

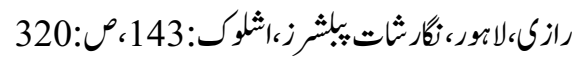

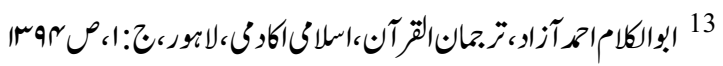

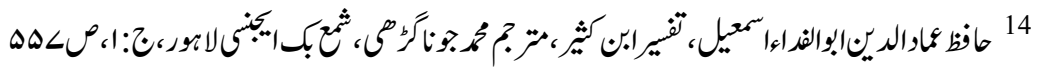

$$
\begin{aligned}
& 15
\end{aligned}
$$

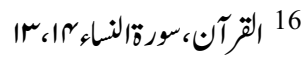

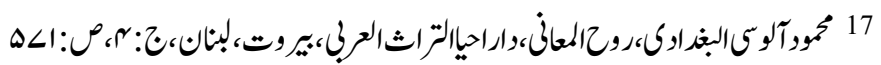

$$
\begin{aligned}
& 18 \text { القرآن، بورة/النساء:كا } \\
& 19
\end{aligned}
$$




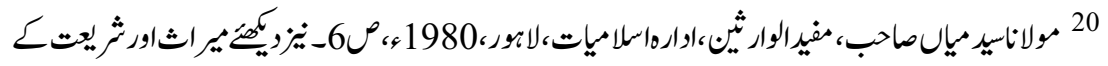

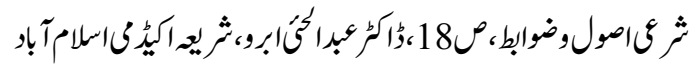

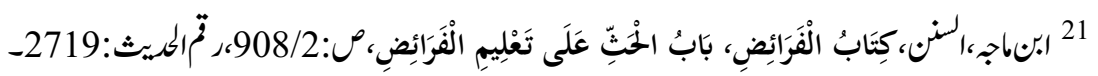

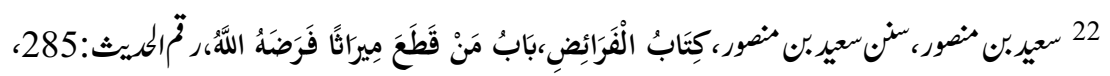
ص:118/1-

23

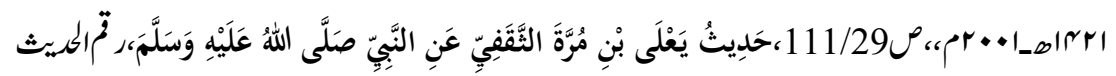
-17571:

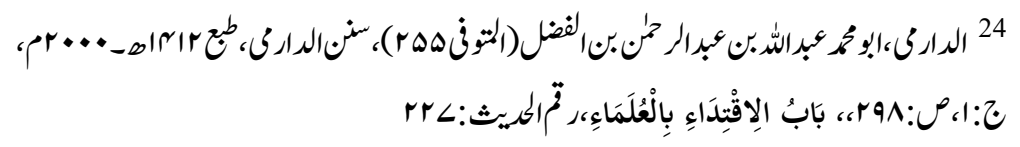

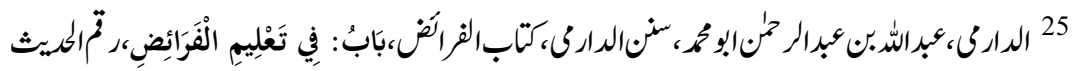
1885/4:2892:

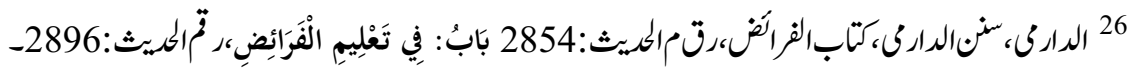
ص:1887/4

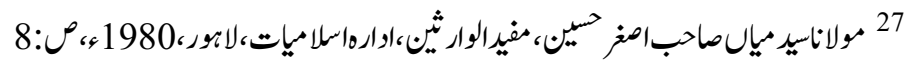

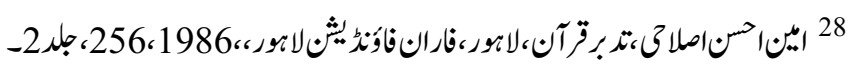
29 الترآن،بورة/النساء||

176:30 12:31

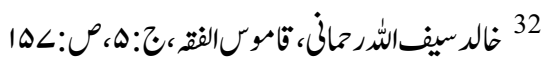
33 34 


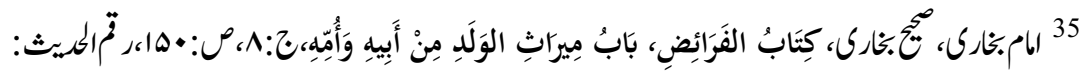
$y<\mu r$

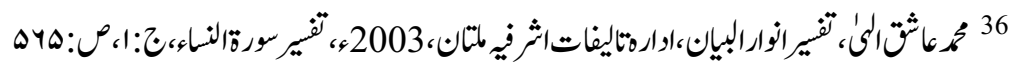
37

38

-https://www.facebook.com/islamicideology.official/posts/697519896943 240

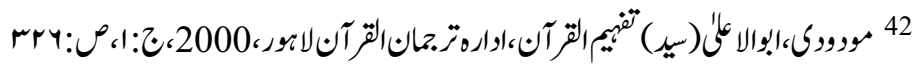

${ }^{43} \mathrm{http} / / /$ www.thefreelancer.com.in/show_article.php?article=105

$$
44
$$

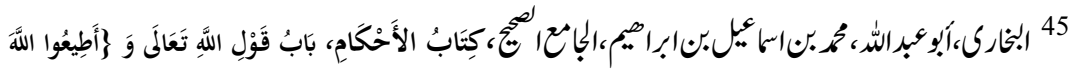

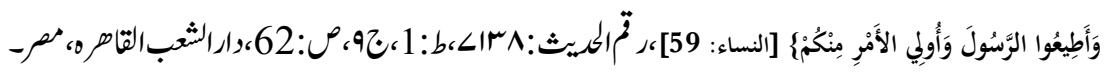

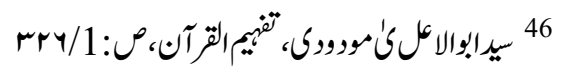

$$
\begin{aligned}
& 47 \text { بورة:النساء:10 } \\
& 48 \\
& 49 \text { سورةالنج • 19،r }
\end{aligned}
$$

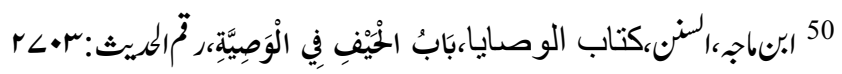

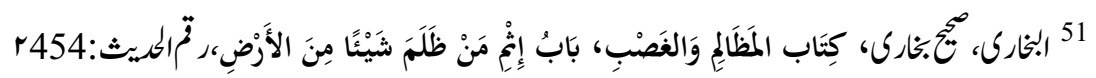

$$
53 \text { سورة|الكثر:7 } 53 \text { سورةالنساء:10 }
$$

